\title{
Transcranial magnetic stimulation for treating depression (Review)
}

Rodriguez-Martin JL, Barbanoj JM, Schlaepfer TE, Clos SSC, Pérez V, Kulisevsky J, Gironell A

Rodriguez-Martin JL, Barbanoj JM, Schlaepfer TE, Clos SSC, Pérez V, Kulisevsky J, Gironell A.

Transcranial magnetic stimulation for treating depression.

Cochrane Database of Systematic Reviews 2002, Issue 2. Art. No.: CD003493.

DOI: 10.1002/14651858.CD003493.

www.cochranelibrary.com 
TABLE OF CONTENTS

ABSTRAC 1

PLAIN LANGUAGE SUMMARY

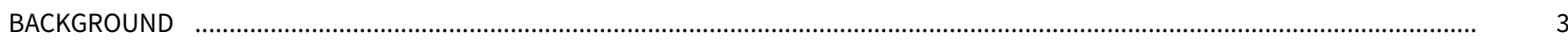

OBJECTIVES

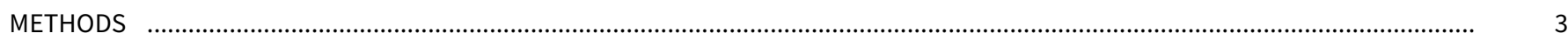

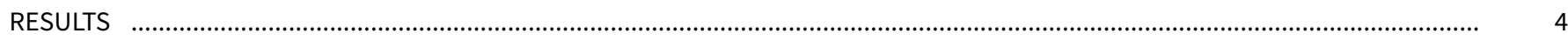

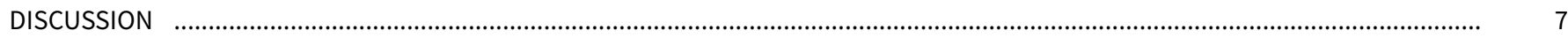

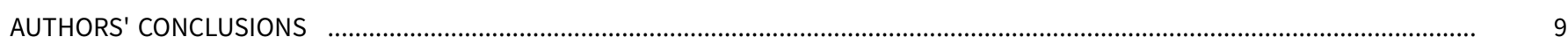

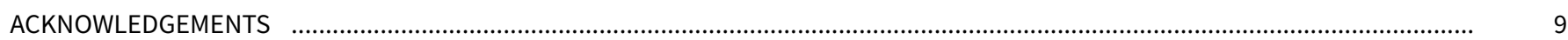

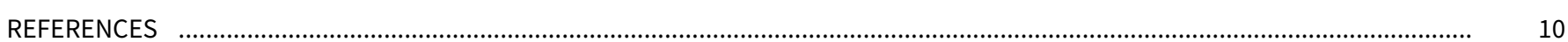

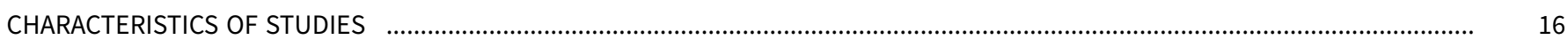

DATA AND ANALYSES

Analysis 1.1. Comparison 1 rTMS (left and high) vs Sham TMS, Outcome 1 Symptoms (Hamilton Scale). ................................... 38

Analysis 1.2. Comparison 1 rTMS (left and high) vs Sham TMS, Outcome 2 Symptoms (Beck Scale). ........................................... 39

Analysis 1.3. Comparison 1 rTMS (left and high) vs Sham TMS, Outcome 3 Clinical Global Improvement. ...................................40

Analysis 2.1. Comparison 2 rTMS (left and low) vs Sham TMS, Outcome 1 Symptoms (Hamilton Scale). .................................... 40

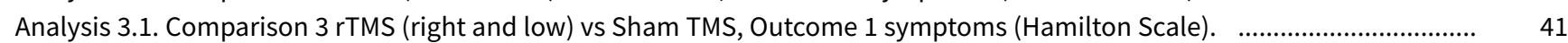

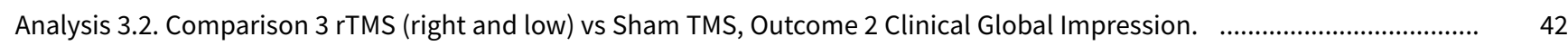

Analysis 4.1. Comparison 4 rTMS (left and high) vs rTMS (left and low), Outcome 1 Symptoms (Hamilton Scale). ....................

Analysis 5.1. Comparison 5 rTMS (mt + 0.3 Tesla) vs rTMS (mt - 0.3 Tesla), Outcome 1 Symptoms (Hamilton Scale). ...................

Analysis 5.2. Comparison 5 rTMS ( $m t+0.3$ Tesla) vs rTMS (mt - 0.3 Tesla), Outcome 2 Clinical Global Impression. ....................... 43

Analysis 6.1. Comparison 6 rTMS (left and high) vs ECT, Outcome 1 Symptoms (Hamilton Scale) all patients. ............................... 44

Analysis 6.2. Comparison 6 rTMS (left and high) vs ECT, Outcome 2 Symptoms (Hamilton Scale) Non-psychotic patients. ....... 45

Analysis 6.3. Comparison 6 rTMS (left and high) vs ECT, Outcome 3 Symptoms (Hamilton Scale) psychotic patients. ...............

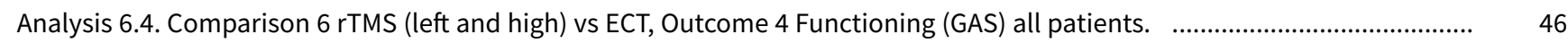

Analysis 6.5. Comparison 6 rTMS (left and high) vs ECT, Outcome 5 Functioning (GAS) non-psychotic patients. ............................. 46

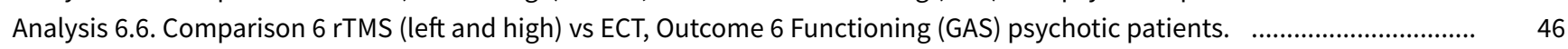

Analysis 7.1. Comparison 7 Acceptability of treatment (rTMS any method of application) vs Sham TMS, Outcome 1 Leaving study 47

early for any reason.

Analysis 8.1. Comparison 8 Baseline scores for Hamilton Depression, Outcome 1 rTMS vs Sham. ...............................................

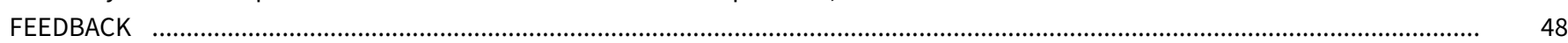

WHAT'S NEW

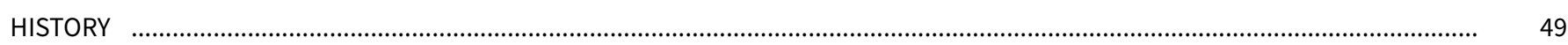

DECLARATIONS OF INTEREST

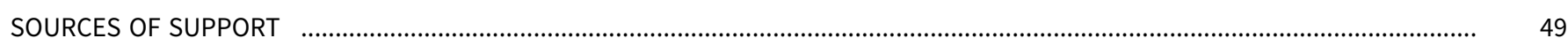

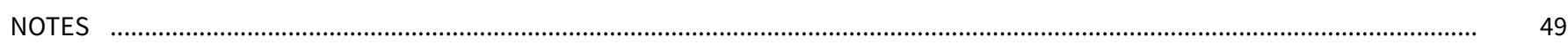

INDEX TERMS 
[Intervention Review]

\title{
Transcranial magnetic stimulation for treating depression
}

\author{
José Luis Rodriguez-Martin¹, José Manuel Barbanoj², TE Schlaepfer ${ }^{3}$, Susana SC Clos ${ }^{4}$, V Pérez5, J Kulisevsky ${ }^{6}$, A Gironell7
}

1School of Biomedical and Health Services, Universidad Europea de Madrid, Madrid, Spain. 2Department of Farmacology, Hospital de la Santa Creu i Sant Pau, Barcelona, Spain. ${ }^{3}$ Department of Psychiatry, University Hospital, Bonn, Germany. ${ }^{4} \mathrm{CIM}$ Sant Pau, Sau Pau, Spain. 5Department of Psychiatry, Hospital de la Santa Creu i Sant Pau, Barcelona, Spain. 6 Movement Disorders Unit, Department of Neurology, Functional Neurosurgery Program for Movement Disorders, Barcelona, Spain. ${ }^{7}$ Movement Disorders Unit, Department of Neurology, Hospital de Sant Pau, Barcelona, Spain

Contact: José Luis Rodriguez-Martin, School of Biomedical and Health Services, Universidad Europea de Madrid, C/Tajo, s/n. Villaviciosa de Odon, Madrid, Madrid, 28670, Spain.jlr.martin@simplifying-research.eu.

Editorial group: Cochrane Common Mental Disorders Group.

Publication status and date: Edited (no change to conclusions), comment added to review, published in Issue 11, 2018.

Citation: Rodriguez-Martin JL, Barbanoj JM, Schlaepfer TE, Clos SSC, Pérez V, Kulisevsky J, Gironell A. Transcranial magnetic stimulation for treating depression. Cochrane Database of Systematic Reviews 2002, Issue 2. Art. No.: CD003493. DOI: 10.1002/14651858.CD003493.

Copyright ( 2018 The Cochrane Collaboration. Published by John Wiley \& Sons, Ltd.

\section{A B S T R A C T}

\section{Background}

Transcranial magnetic stimulation can either excite or inhibit cortical areas of the brain, depending on whether the speed of the repetitive stimulation is applied at high or low frequencies. It has been used for physiological studies and it has also been proposed as a treatment for depression.

\section{Objectives}

To assess the clinical efficacy and safety of transcranial magnetic stimulationfor treating depression.

\section{Search methods}

An electronic search was performed including the Cochrane Collaboration Depression, Anxiety and Neurosis Review Group trials register (last searched June 2001), the Cochrane Controlled Trials Register (Issue 2, 2001), MEDLINE (1966-2001), EMBASE (1974-2001), PsycLIT (1980-2001), and bibliographies from reviewed articles. Unpublished data and grey literature were searched through personal communications with researchers.

\section{Selection criteria}

Randomised controlled trials assessing the therapeutic efficacy and safety of transcranial magnetic stimulation for depression.

\section{Data collection and analysis}

All reviewers independently extracted the information and verified it by cross-checking. Disagreements were resolved through discussion. Continuous data: When similar studies were grouped, the overall standardised mean difference was calculated under a fixed effect model weighted by the inverse variance method with 95\% confidence intervals. (In the presence of statistical heterogeneity, a random effects model was to be used.)

\section{Main results}

Sixteen trials were included in the review and fourteen contained data in a suitable form for quantitative analysis. Most comparisons did not show differences between rTMS and other interventions. No difference was seen between rTMS and sham TMS using the Beck Depression Inventory or the Hamilton Depression Rating Scale, except for one time period (after two weeks of treatment) for left dorsolateral prefrontal cortex and high frequency; and also for right dorsolateral prefrontal cortex and low frequency, both in favour of rTMS and both using 
the Hamilton scale. Comparison of rTMS (left dorsolateral prefrontal cortex and high frequency) with electroconvulsive therapy showed no difference except for psychotic patients after two weeks treatment, using the Hamilton scale, which indicated that electroconvulsive therapy was more effective than rTMS.

\section{Authors' conclusions}

The information in this review suggests that there is no strong evidence for benefit from using transcranial magnetic stimulation to treat depression, although the small sample sizes do not exclude the possibility of benefit.

\section{PLAIN LANGUAGE SUMMARY}

\section{Transcranial magnetic stimulation (TMS) for depression}

Transcranial magnetic stimulation can either excite or inhibit cortical areas of the brain, depending on whether the speed of the repetitive stimulation is applied at high or low frequencies. It has been used for physiological studies and it has also been proposed as a treatment for depression. Sixteen trials were included in the review and fourteen contained data in a suitable form for quantitative analysis. Most comparisons did not show differences between repetitive (rTMS) and other interventions. No difference was seen between rTMS and sham TMS using the Beck Depression Inventory or the Hamilton Depression Rating Scale, except for one time period (after two weeks of treatment) for left dorsolateral prefrontal cortex and high frequency; and also for right dorsolateral prefrontal cortex and low frequency, both in favour of rTMS and both using the Hamilton scale. Comparison of rTMS (left dorsolateral prefrontal cortex and high frequency) with electroconvulsive therapy showed no difference except for psychotic patients after two weeks treatment, using the Hamilton scale, which indicated that electroconvulsive therapy was more effective than rTMS. 


\section{B A C K G R O U N D}

Transcranial magnetic stimulation (TMS) was introduced as a neurophysiological technique in 1985 when Anthony Barker and his team developed a compact machine that permits a noninvasive stimulation of the cerebral cortex (Barker 1985). Since its introduction, TMS has been used for the evaluation of the motor system, for the functional study of several cerebral regions, and for the physiological study of several neuropsychiatric illnesses. In addition, it has been postulated that TMS could be a therapeutic tool.

Repetitive transcranial magnetic stimulation (rTMS) is a type of TMS that occur in a rhythmic and repetitive form. If the stimulation occurs faster than once per a second $(1 \mathrm{~Hz})$ it is called high frequency rTMS whereas if the speed of stimulation is equal or less than $1 \mathrm{~Hz}$ it is called low frequency rTMS. Low frequency rTMS is considered to inhibit cortical stimulation in certain regions, while high frequency rTMS activates stimulated areas. This capability for excitation or inhibition of cortical areas in a non-invasive way represents a remarkable advance in neuroscience research.

In the last five years there have been an increase in controlled studies evaluating the therapeutic effects of rTMS technique in depressive patients (George 1995 b; Kolbinger 1995; George 1997; Haag 1997; Avery 1999; Kimbrell 1999; Loo 1999; Klein 1999; Berman 2000 b; Grunhaus 2000; Speer 1999; García-Toro 2001 a). The initial results of these studies have suggested that rTMS could be an important therapeutic method for this condition, and in order to discover and systematise its procedures better, studies have also focused on comparing different programs of administration.

The mood (affective) disorders (APA 1994) (WHO 1993) include a collection of categories where the primary characteristic is a mood alteration. Depressive disorders (major depressive disorder, dysthymic disorder or depressive disorder not otherwise specified), and bipolar disorders (bipolar (affective) disorders I \& II, cyclothymic disorder and bipolar disorder not otherwise specified) are the main categories. The mood (or affective) alterations are normally based either in depressive symptoms (with or without anxiety) or in euphoria. The symptoms of depressive disorders include a depressed mood most of the day, decrease interest in all daily activities, significant weight loss, insomnia or hypersomnia, loss of energy, diminished ability to think or concentrate, recurrent thoughts of death (suicidal ideation or suicidal attempt). The symptoms of bipolar disorders include either the previous described symptoms for depressive disorders and periods of abnormally elevated or irritable mood, decreased need for sleep, psychomotor agitation, distractibility, inflated selfesteem or grandiosity. The symptoms of these mental disorders cause significant psychological distress and social or occupational impairment for patients and their relatives.

In many cases, this symptomatology is recurrent over years, and in some cases the disease has a chronic course and a high nonresponse rate to conventional pharmacotherapy.

This systematic review aims to evaluate current evidence concerning transcranial magnetic stimulation technique as a therapeutic treatment for depression, categorised as depressive disorders or bipolar disorders in depressed phase, with or without psychotic symptoms.

\section{O B JECTIVES}

To assess the clinical efficacy and safety of the transcranial magnetic stimulation for treating depression.

\section{METHODS}

\section{Criteria for considering studies for this review Types of studies}

Randomised controlled trials assessing the therapeutic efficacy and safety of the transcranial magnetic stimulation for depression. Quasi-random study designs were excluded.

\section{Types of participants}

All persons with depression (depressive disorders or bipolar disorders in depressed phase) diagnosed by any recognised criteria, irrespective of gender, age or nationality.

\section{Types of interventions}

A) The application of transcranial magnetic stimulation technique versus:

1. No intervention.

2. Sham transcranial magnetic stimulation.

3. Psychotherapy treatment (sub-group analysis by different types of therapy).

4. Psychotropic drugs (sub-group analysis by different types of drugs).

5. Any other therapy (apart from drug and psychological therapies). 6. (r)TMS + other therapies or drugs versus sham (r)TMS + the same therapies or drugs.

B) Different methods of application of transcranial magnetic stimulation:

1. High frequency vs low frequency.

2. Right dorsolatreral prefrontal cortex versus left dorsolateral prefrontal cortex.

3. Single pulse versus repetitive pulse.

\section{Types of outcome measures}

The outcomes of principal clinical interest are:

a) Remission of symptoms

b) Short, medium and long term functioning

c) Individual/social behaviour

d) Quality of life

e) Global impression

These measures were assessed for each group through specific standardised scales.

f) Acceptability of treatment (as measured by withdrawal from trial) g) Safety as measured by the incidence of adverse effects (including side-effects )

h) Hospitalisation rates

i) Mortality.

\section{Search methods for identification of studies}

See: Collaborative Review Group search strategy.

The Cochrane Collaboration Depression, Anxiety and Neurosis review group's search strategy and the Iberoamerican Cochrane Centre search strategy were used to search MEDLINE 
(1966-2001), EMBASE (1974-2001), PsycLIT (1980-2001), the Cochrane Collaboration Depression, Neurosis and Anxiety Review Group trials register (last searched June, 2001), the Cochrane Controlled Trials Register (Issue 2, 2001). Date of last search in MEDLINE: 18 June 2001.

Unpublished data and grey literature were searched through personal communications with researchers and others with an interest in the field. Our search included all languages. When possible, the corresponding authors of identified RCTs were contacted for additional information about other relevant studies.

\section{Data collection and analysis}

The previously published protocol has been adapted during development of this review.

\section{Study selection}

The reviewers independently evaluated all the identified articles without previously taking into consideration the results. The number of articles found and the experience of the reviewers on this subject made blinding of authors, institutions, journals or results of the identified articles impossible. Potentially relevant summaries were identified from the references retrieved from the search, and the complete text was obtained for an evaluation of its methodological quality. Disagreements were resolved through discussion.

\section{Quality assessment}

The quality of the method of random allocation and of concealment of allocation followed in every selected trial was assessed using the methods described in the Cochrane Collaboration Handbook (Clarke 2001).

Trials with unclear concealment measures have been shown to yield more pronounced estimates of treatment effects than trials that have taken adequate measures to conceal allocation schedules but this effect is less pronounced than with inadequately concealed trials (Schulz 1995). Thus trials classified in categories A (adequate) or $\mathrm{B}$ (unclear) were included in the quantatitive analysis of this review, and those classified in category $C$ (inadequate) were excluded from this analysis.

Heterogeneity between the results of trials was also assessed as part of the quality assessment of the trials.

\section{Data Collection}

All reviewers independently extracted the information and they verified it with cross-checking. Disagreements were resolved through discussion. If doubts persisted and additional information was needed to resolve the dilemma, the author of the study was contacted to clarify the disagreements between the reviewers.

\section{Data synthesis}

In the cross-over studies we tried to exclude a possible carryover effect between the different phases of the trials using only information from the first phase of the studies.

Cross-over studies should not be used in studies with curable or lethal conditions, as well as in studies evaluating pathology or unstable conditions (Jadad 1998).

Incomplete data: it was agreed not to include studies with more than $40 \%$ withdrawals in the final quantitative analysis, as this level of withdrawal could threaten the validity of the results. Variations

Transcranial magnetic stimulation for treating depression (Review)

Copyright (c) 2018 The Cochrane Collaboration. Published by John Wiley \& Sons, Ltd. in the validity can explain variations of the results included in a systematic review.

In the context of a systematic review the validity of a study is related to the degree in which bias and random error can be minimized (Moher 1995).

Continuous data: for the continuous variables (psychometric test scores, scales of global clinical impression) in individual studies the results are calculated as weighted mean differences under a fixed effect model, weighted by the inverse variance method and with $95 \%$ confidence intervals (Cls). When similar studies are grouped, the overall standardised mean difference was calculated under a fixed effect model weighted by the inverse variance method with $95 \% \mathrm{Cls}$. It was assumed that homogeneity existed from the chisquare test when $p>0.10$, but if this was not the case, a random effects model (DerSimonian and Laird method) was to be used.

Information from rating scales or self-applied questionnaries would not be compared in the same analysis, and so separate analyses for each one of these methods were created.

We aimed to make direct comparisons between the trials which used the same instruments of measuring for quantifying specific variables. The comparison of data through different scales can be problematic and can affect internal validity. For example the Hamilton Depression Rating Scale gives more importance to somatic and behavioural symptoms than to psychological manifestations of depression, with its objective of the quantifying the results of a semi-structured interview. The Beck Depression Inventory is a self-administered questionnaire which was developed by a clinical approximation of psychoanalytical therapy when treating depressed patients and gives more importance to cognitive components than somatic and behavioural components of depression.

Binary data: for the binary outcomes the relative risk under a fixed effect model by Mantel-Haenszel model with $95 \% \mathrm{Cls}$. In the case of finding statistical heterogeneity, a random effects model (DerSimonian and Laird method) was to be used.

Heterogeneity: it was agreed to evaluate clinical heterogeneity by using a careful evaluation of quality, the populations, the interventions and the outcomes within every study. Statistical heterogeneity of trial results was evaluated by an inspection of the graphs and calculating chi-square tests. It was also agreed to investigate the presence of possible publication bias through funnel plots.

\section{RE S U L T S}

\section{Description of studies}

Through searches in electronic databases and internet, bibliographies of selected articles, journals and direct communication with the researchers we obtained seventy nine studies which potentially fulfilled our inclusion criteria. Out of these studies, eighteen are currently still underway and/or awaiting approval through the respective editorial processes. We have used quantitative and qualitative data from two of these studies, which after their evaluation were able to be included in this review, leaving 16 studies in the ongoing studies category.

Seven of the studies found were not published in English and an objective valuation was obtained by summaries in English, or 
with the help of different international centres of the Cochrane Collaboration. None of these studies obtained the minimum classification to be included in the analysis of this review, principally for not being randomised studies.

Included studies

Sixteen studies have been included in the Characteristics of Included studies table.

Two studies classified as included studies (Conca 1996 and Pridmore $2000 \mathrm{~b}$ ) were not able to be analysed quantitatively due to methodological problems in these studies (see Characteristics of included studies table).

\section{Excluded studies}

Forty-five studies were excluded from the quantitative analysis of this review (not including the studies listed as ongoing). The main reasons for exclusions were no randomisation of the patients to the different interventions, inadequate randomisation (category C), the lack of a randomised control group, narrative reviews, descriptive studies and studies with healthy volunteers (see Characteristics of excluded studies table).

\section{Awaiting assessment}

Two studies (Pascual-Leone 1996) and (Speer 2000) are awaiting evaluation of design data and methodological quality to be included, and additional quantitative information is needed for these studies to be analysed.

\section{Risk of bias in included studies}

\section{Randomisation and allocation concealment.}

All studies included in the statistical analysis of this review are included in category B (unclear), as they do not describe the method of concealment allocation used and only give general descriptions or describe the method of generation of the allocation sequence. (Information should be presented that provides some assurance that allocations were not known until, at least, the point of allocation (Clarke 2001). Klein 1999 describes only the generation of the allocation sequence, through randomised lists of numbers generated by a computer programme. Grunhaus 2000 describes the method of randomisation only as "a priori generated list" but without giving the method of concealment allocation. Mosimann In Pressinforms of "generation of randomized numbers" but without describing the process. Pridmore 2000 a explicitly uses an inadequate method of randomization (category $\mathrm{C}$ ) as the allocation of treatment is by order of presentation. This study has been excluded from the analysis and is described separately with the excluded studies. Conca 1996 and Pridmore 2000 b have been retained in the included studies section, but have been excluded from the quantitative analysis. This is because despite fulfilling the requirements of randomization, it was not possible to differentiate the placebo effect from the effect of treatment from their designs; for example, in these studies a dummy design is essential to equalise the groups.

Blinding of interventions in patients and researchers.

Twelve of the sixteen studies included in the review are clearly described as double-blind or double-masked. In these interventions it is impossible to blind the professional who applies the technique to their patients (i.e. the physician who applies the treatment or control) and double-blind in this case refers to the patient and outcome assessor. Kimbrell 1999 and Avery 1999 follow this same procedure of blinding patients and outcome assessors, although they do not explicitly state "double blind" and thus have been included as double-blind. Grunhaus 2000 is the only open trial study included in the statistical analysis of the review. We chose to include this study because of the methodological impossibility of blinding two experimental conditions of very different application.

Follow up.

All the studies included in the quantitative evaluation of this review described the withdrawals during the study. Only two studies, Berman $2000 \mathrm{~b}$ and Eschweiler 2000 used the last observation carried forward, the rest of the studies which had withdrawals did not include these patients in the analysis. However the majority of trials had small numbers of patients and some of these trials noted that there were no withdrawals.

Three studies, Avery 1999; García-Toro 2001 c(in editorial process), and García-Toro 2001 ainclude a period of post-treatment follow up of two weeks and one study, Eschweiler 2000 includes a period of post-treatment follow up of one week between the first and second phase of the cross-over design. The Berman $2000 \mathrm{~b}$ study used the post-treatment follow up for only one patient who responded totally and for three who responded partially, but it does not refer to the rest of the patients treated in the study.

To prevent possible attrition bias, ideally results for all randomised patients should be included and analysed.

Evaluation of depressive symptoms.

To collect and analyse information with regards to depressive symptomatology in patients, we tried to use the most homogenous method possible. This was by direct analysis between studies which used the same instrument of measure, since comparing results with continuous data through different scales of measure is problematic. The Hamilton Depression Rating Scale has been used as a primary outcome in all the studies analysed, whereas the Beck Depression Inventory questionnaire has been the most used as a secondary self-administered evaluation. Both these scales of evaluation of symptoms have been used in this metaanalysis. We have taken into account that the Hamilton Scale and Beck Inventory have been used in their different versions, which is why the pooled analysis was carried out by standardised mean difference. Analysable data is presented from all the studies included in this review for the Hamilton scale, but not for the Beck self-applied questionnaire. Subsequently the principal researchers of each study working with this questionnaire were contacted and asked for the data in mean SD.

Methods of evaluating.

Whether in random form (probably due to a low number of patients per study) or systematic form (for example uncertain concealment of allocation) most of the studies in this review have higher baseline values for the Hamilton scale, in patients included in the treatment group compared to those in the placebo group. We therefore performed an overall analysis of all the studies (rTMS versus placebo) to determine if there were possible initial (baseline) differences for this variable. The fourteen studies analyzed in this comparison show statistical homogeneity, chi-square: 13.37, df $=13, p=0.42$. This difference was statistically significant with treated patients having a higher (worse) Hamilton score at baseline than the placebo group; standardised mean difference with a fixed effect model, for the treatment group versus the placebo group in baseline condition $0.30(95 \% \mathrm{Cl} 0.06$ to $0.54 ; \mathrm{p}=0.02)$. 
For this reason and to prevent an increase of regression to the mean in the treatment group when comparing with the placebo group the evaluation of the change scores from baseline (i.e. pre-randomization or at randomization) to the final assessment between the two groups was not advisable. Therefore it was decided to only use final values of both groups. The clinical interpretation of this comparison is the difference in the level of depression in the patients at the end of the studies between both groups.

\section{Description of the scales:}

Hamilton Depression Rating Scale: scale generally used in psychopharmaceutical studies with depressed patients. Various versions exist with different numbers of items. Its objective is the quantification of the results of a semi-structured interview. This scale gives more importance to somatic and behavioural symptoms than to psychological manifestations of depression. To increase reliability of the observations, it was recommended that the scale be used by two observers, one to do the interview and the other to ask complementary questions. Both register their scores separately and then sum them after the interview to give the rating. It was recommended that when ratings are repeated they should be made independently and the interviewer should not have documentation of the previous evaluation. Low values indicate less depression.

Beck Depression Inventory: self-applied questionnaire which was developed by a clinical approximation by psycho-analytical therapy when treating depressed patients. Various versions exist. This questionnaire gives more importance to cognitive components than somatic and behavioural components of depression. The final value of this questionnaire is estimated as a level of measuring the depression of the patient independently from the diagnosis. Low values indicate less depression.

Global Assessment Scale - GAS. From 0 to 100 points. This scale gives a global measure of functioning and symptomatology. High values indicate better functioning.

Clinical Global Impression - CGI. Instrument of evaluation for the severity of the illness. This scale consists of three subscales each of which is a global item. Two of these items, "severity of illness" and "global improvement" are composed of a scale of seven points, while the third item "index of efficacy" requires a classification resulting from the interaction between therapeutic efficacy and adverse reactions. Low values indicate a decrease in the severity and/or significant recuperation.

\section{Effects of interventions}

Analysis of efficacy

\section{rTMS (left dorsolateral prefrontal cortex and high frequency) versus sham TMS}

Outcome: depressive symptoms.

1. Hamilton Depression Rating Scale. Eleven studies have contributed to this analysis with an overall sample of 197 patients (109 in the treatment group and 88 in the placebo group). Subgroup analysis was carried out with a period of time of one week after treatment with and without a week of post-treatment, two weeks of treatment with and without two weeks of post-treatment. None of the comparisons indicated that there was statistical heterogeneity and so a fixed effects model was chosen. The comparison with the highest number of studies was with two weeks of treatment. After one week of treatment, the standardized mean difference (SMD) for the rTMS over the left dorsolateral prefrontal cortex and high frequency versus sham TMS, was $0.02(95 \% \mathrm{Cl}-0.66$ to $0.70 p=1 ; n=3$ studies). After a week of treatment plus a week of post-treatment follow-up the weighted mean difference (WMD) between rTMs and placebo was $3.80(95 \% \mathrm{Cl}-4.01$ to $11.61 \mathrm{p}=0.3$; $\mathrm{n}=1$ study). After two weeks treatment the SMD was $-0.35(95 \% \mathrm{Cl}$ -0.66 to $-0.04 ; p=0.03 ; n=9$ studies), showing a difference in favour of rTMS. After two weeks of post-treatment follow up, the SMD was $-0.33(95 \% \mathrm{Cl}-0.84$ to $0.17 ; \mathrm{p}=0.2 ; \mathrm{n}=3$ studies), which is no longer statistically significant.

2. Beck Depression Inventory. Seven studies contribute to this analysis with an overall size of 145 patients ( 81 in the treatment group and 64 in the placebo group). The same subcategories of analysis were carried out for the same time periods as in the previous analysis. None of the comparisons indicated that there was statistical heterogeneity and so a fixed effects model was chosen. No difference between rTMs and sham TMS was shown for any of the time periods. After one week of treatment, the SMD for the rTMS over the left dorsolateral prefrontal cortex and high frequency versus sham TMS, was 0.18 ( $95 \%$ CC -0.47 to $0.82 ; p=$ $0.6 ; n=3$ studies). After one week of post-treatment follow up the weighted mean difference for only one study was $6.60(95 \% \mathrm{Cl}-7.54$ to $20.74 ; p=0.4$ ). The SMD after two weeks of treatment was -0.24 ( $95 \% \mathrm{Cl}-0.58$ to $0.11 ; p=0.18 ; n=6$ studies). The SMD after two weeks of post-treatment follow up was $-0.06(95 \% \mathrm{Cl}-0.56$ to 0.43 ; $\mathrm{p}=0.8 ; \mathrm{n}=3$ studies).

Outcome: global impression.

1. Clinical global improvement. One study contributes to this analysis with a total sample size of 30 patients ( 20 in the treatment group and 10 in the placebo group). The WMD for the rTMS over the left dorsolateral prefrontal cortex and high frequency versus sham TMS, after two weeks of treatment was -0.70 (95\% IC -1.77 to 0.37 ; $\mathrm{p}=0.2$ ) which was not statistically significant.

\section{rTMS (left dorsolateral prefrontal cortex and low frequency) versus sham TMS.}

Outcome: depressive symptoms.

1. Hamilton Depression Rating Scale. Two studies contribute to this analysis with an overall sample size of 20 patients (11 in the treatment group and 9 in the placebo group). After one week of treatment, the WMD for the rTMS over the left dorsolateral prefrontal cortex and low frequency versus sham TMS was -2.00 ( $95 \% \mathrm{Cl}-13.49$ to $9.49 ; \mathrm{p}=0.7 ; \mathrm{n}=1$ study). After two weeks of treatment the WMD was $2.53(95 \% \mathrm{Cl}-13.53$ to $18.59 ; \mathrm{p}=0.8 ; \mathrm{n}=1$ study), so no statistically significant difference was shown for either time period.

\section{rTMS (right dorsolateral prefrontal cortex and low frequency) versus sham TMS}

\section{Outcome: depressive symptoms.}

1.Hamilton Depression Rating Scale. A single study contributes to this analysis with a sample size of 67 patients, ( 35 in the treatment group and 32 in the placebo group). After one week of treatment, the WMD for the rTMS over the right dorsolateral prefrontal cortex and low frequency versus sham TMS $-4.20(95 \% \mathrm{Cl}-8.44$ to $0.04 ; \mathrm{p}$ 
$=0.05)$. After two weeks of treatment, the WMD was $-6.00(95 \% \mathrm{Cl}$ - 10.69 to $-1.31 ; p=0.01$ ). Thus there was a statistically significant result in favour of rTMS at two weeks, but not at one week.

Outcome: global impression.

1. Clinical Global Impression. After one week of treatment, the same trial as above shows a WMD for the rTMS over the right dorsolateral prefrontal cortex and low frequency versus sham TMS of -0.50 (95\% $\mathrm{Cl}-1.11$ to $0.11 ; \mathrm{p}=0.11)$. After two weeks of treatment, the WMD was $-0.70(95 \% \mathrm{Cl}-0.40$ to $0.00 ; p=0.05)$, which becomes just statistically significant.

rTMS (left dorsolateral prefrontal cortex and high frequency) versus rTMS (left dorsolateral prefrontal cortex and low frequency)

Outcome: depressive symptoms.

1. Hamilton Depression Rating Scale. Two studies contribute to this analysis with an overall sample size of 22 patients (11 in the high frequency group and 11 in the low frequency group). After one week of treatment, the WMD for the rTMS over the left dorsolateral prefrontal cortex and high frequency versus rTMS with low frequency was -2.60 ( $95 \% \mathrm{Cl}-10.76$ to $5.56 ; \mathrm{p}=0.5 ; \mathrm{n}=1$ study). After two weeks of treatment, the WMD was $-0.40(95 \% \mathrm{Cl}-13.84$ to $13.04 ; p=1 ; n=1$ study), with neither period showing a statistically significant difference between high and low frequency.

rTMS (vertex motor localisation +0.3 tesla) versus rTMS (vertex motor localisation $-\mathbf{0 . 3}$ tesla)

Outcome: depressive symptoms.

1. Hamilton Depression Scale. A single study contributes to this analysis with a sample size of 5 patients in the group of +0.3 tesla and 5 patients in the group -0.3 tesla. The analysis was for a period of time of one week. The WMD for the rTMS vertex motor +0.3 tesla versus vertex motor -0.3 tesla after one week of treatment was $6.40(95 \% \mathrm{CIC}-1.71$ to $14.51 ; p=0.12)$, which was not statistically significant.

Outcome: global impression.

1. Clinical Global Impression. The same study shows a WMD for the rTMS vertex motor +0.3 tesla versus vertex motor -0.3 tesla after one week of treatment of $0.40(95 \% \mathrm{Cl}-1.33$ to $2.13 ; \mathrm{p}=0.6)$ which is not statistically significant.

rTMS (left dorsolateral prefrontal cortex and high frequency) versus ECT (electroconvulsive therapy)

Outcome: depressive symptoms.

1. Hamilton Depression Rating Scale. A single study contributes to this analysis with a sample size of 40 patients ( 20 in the rTMS group and 20 in the ECT group). This study used three comparisons (the whole sample, only patients with psychotic symptoms and only patients without psychotic symptoms). After two weeks of treatment, the WMD for the rTMS with left dorsolateral prefrontal cortex and high frequency versus ECT for all patients was 1.70 (95\% $\mathrm{Cl}-3.27$ to $6.67 ; \mathrm{p}=0.5)$. After four weeks the result was also statistically non-significant, WMD $4.20(95 \% \mathrm{Cl}-0.74$ to $9.14 ; \mathrm{p}=$ 0.10).
2. For the non-psychotic patients the WMD after two weeks was $-3.90(95 \% \mathrm{Cl}-10.90$ to $3.10 ; \mathrm{p}=0.3)$. After four weeks of treatment the WMD was $-2.90(95 \% \mathrm{Cl}-10.26$ to $4.46 ; \mathrm{p}=0.4)$, again statistically non-significant for both time periods.

3. For the psychotic patients the WMD after two weeks was 7.90 (95\% $\mathrm{Cl} 1.98$ to $13.82 ; \mathrm{p}=0.009)$ in favour of ECT. After four weeks this positive result in favour of ECT was increased, WMD 12.40 (95\% $\mathrm{Cl} 7.77$ to 17.03 ; $p<0.00001$ ).

Outcome: functioning

1. Global Assessment Scale - GAS. This study also evaluates functioning and symptomatology on a global scale. Three comparisons were also carried out here (the whole sample, only patients with psychotic symptoms and only patients without psychotic symptoms). After two weeks of treatment, the WMD for the rTMS over the left dorsolateral prefrontal cortex and high frequency versus ECT for all patients was $-2.30(95 \% \mathrm{Cl}-12.22$ to $7.62 ; \mathrm{p}=0.6)$. After four weeks the WMD t was $-10.50(95 \% \mathrm{Cl}-22.85$ to $1.85 ; p=0.10$ ), giving a statistically non-significant result for both time periods.

2. For the non-psychotic patients the WMD after two weeks was $8.40(95 \% \mathrm{Cl}-5.10$ to $21.90 ; \mathrm{p}=0.2)$ and after four weeks the WMD was $3.00(95 \% \mathrm{Cl}-14.61$ to $20.61 ; p=0.7)$, giving a statistically nonsignificant result for both time periods.

3. For the psychotic patients the WMD after two weeks was -14.50 (95\% Cl -27.04 to $-1.96 ; p=0.02)$ in favour of ECT. After four weeks this positive result also favoured ECT, WMD -26.10 ( $95 \% \mathrm{Cl}-41.12$ to -11.08; $p=0.0007$.

Acceptability of treatment

\section{rTMS (Any method of application) versus sham TMS:}

Outcome: withdrawals during the study (for whatever reason)

Five studies reported withdrawals of patients during interventions, with a total sample size of 184 patients (99 in the treatment group and 85 in the placebo group). The five studies analysed in this comparison show statistical homogeneity. The relative risk, using a fixed effect model, for the rTMS (whatever method of administration) versus sham TMS, for all patients was 0.81 (95\% IC 0.36 to $1.83 ; p=0.6$ ), a statistically non-significant difference.

\section{DISCUSSION}

The principal deficiency in methodology this review has come up against is probably the small sample size of the studies. Apart from one study with seventy patients (Klein 1999), the rest used sample sizes of between six and forty patients (median = 19). The process of randomization may not be able to guarantee the equality of groups in all their variables. None of the included studies in this review describe the method of concealment allocation used, indicating only that the study was randomized or describing only the generation of the allocation sequence (e.g. computer). In these cases it is impossible to determine whether a possible influence (direct or indirect) has existed in the allocation of the patients to different groups of intervention. For example, in certain randomized controlled trials the patients who are most likely to respond are included only in the active treatment arm (Berger 1999). The selection bias which is produced in circumstances like 
this, can influence the final results of the studies by overestimating a possible effect of treatment (Chalmers 1992). Selection bias is one of the principal threats to the internal validity of randomized controlled trials.

The principal method for trying to eliminate performance bias (different levels of attention provided to treatment and control groups) is the process of blinding. Most of the studies included in this review are described as double blind, although the professional in charge of applying the technique of magnetic stimulation must know whether each patient belongs to the treatment or the control group. These trials differing from other double-blind trials, principally pharmaceutical, where the active compound and the placebo are administered in identical format, texture and colour. Since it is impossible to have authentic double blinding in these trials, it is more advisable to talk about single blind with evaluation by external blinded assessors (it is common even in open trials to use evaluation by external blinded assessors). The principal reason for differentiating this type of design is the possible increase in the probability of biases related to the performance of the studies. These systematic errors can appear in both a conscious or an unconscious form such as an expectation bias of positive results, from researchers aware of the conditions of the test and in contact with the patients, especially if there is subjectivity in the evaluation method (Day 2000). The interaction of the patients with the researchers in charge of the application of the technique could be providing different levels of motivation to both participants.

This limitation of not being able to completely blind this type of intervention should be addressed by a stricter methodology to balance the possible incidence of the biases previously described. Recording the sessions and giving them to different evaluators (without knowledge of the procedure of application in this technique) so that they can try and deduce which group each patient belongs to, could be a possible compromise. The possible motivation of the patient, as already mentioned, is increased with the possible expectation of the evaluators in the studies. In Berman 2000 b, patients deduced their groups in ten out of fifteen evaluations, while the evaluators deduced the groups of the patients in twelve out of fifteen cases.

Other outcome measures like numbers of readmissions to hospital, hospital discharges, time to adjunctive treatment and/or time off work are being considered for studies with psychiatric patients, in order to resolve methodological problems with scales and/ or inventories. The Hamilton scale is the most common scale used in clinical studies of depressive patients; however, scales based on semi-structured interviews are more susceptible to a possible observation bias than the self-applied questionnaires (Hotopf 1999). All the studies in this review have used the Hamilton scale as a primary outcome, finding a positive global effect in the comparison of high frequency and left localisation versus placebo after two weeks of treatment; however, this positive effect disappears in the same comparison by using the Beck self-applied questionnaire. Despite the fact that this last comparison with Beck's questionnaire used less studies, due to lack of numerical data (in mean and SD) in some studies, these differences in function of the type of scale are not able to determine the true cause of the change in patients. It is also interesting to highlight that the only study on an individual level which, in this review, finds an effect in favour of the intervention of the previous comparison using the
Hamilton scale (Berman 2000 b), shows that no differences exist between groups for the Beck questionnaire.

In randomized controlled trials which use relatively large sample sizes, the possible biases when applying self-applied questionnaires (for example answering systematically in the same way) should not have a different effect on the different groups in the study, i.e. they would be balanced in all of the groups (supposing that the concealment allocation has been correct). In experimental studies it is clinically more important to detect a change when measuring the psychopathology than to detect precision in the measure (Hotopf 1999). On the other hand, a Rasch item analysis at the Hamilton scale has shown that this scale could be heterogeneous and that the scores of the total sum of its items might not be a suitable measure of the severity of depression (Rosenberg 2000). For these reasons we assume that in this review the comparisons of the self-applied questionnaire are more reliable than the comparisons made by the rating scale.

Two comparisons showed positive effects in favour of the rTMS versus placebo. The first comparison (high frequency and left localization over two weeks in symptoms evaluated with the Hamilton scale) has used the most number of studies, but these studies are, as previously mentioned, pilot studies with very small number of patients samples and they do not adequately describe the method of allocation concealment used. (A sub-group analysis made for only refractory patiens does not change the result of this comparison.) The second comparison with positive results (low frequency and right localization over two weeks in symptoms evaluated with the Hamilton scale and with Clinical Global Impression) used only one study (Klein 1999), but in this case its methodological quality is superior to the other included studies, owing to a larger number of patients. However, in this study an elevated intragroup variability appears with a coefficient of variation $>0.5$, exactly 0.67 in the treated group and 0.52 in the placebo group, at the end of the comparison. This level of dispersion shows that the mean is not likely to be a representative measure in this study, probably due to the heterogenity of the sample used.

When rTMS was compared to ECT, no significant differences appeared between these two techniques when the patients did not have psychotic symptoms, but significant differences did appear in favour of the ECT when the patients had psychotic symptomatology. These comparisons are not free from the methodological deficiencies previously mentioned, especially because of the open character of the study (including the evaluators).

It does not seem, however, that the use of this technique, with its usual safety measures, produces significant adverse effects in the short-term (from one to three or four weeks), apart from in some cases a moderate headache which is easily treated. The criteria of patients inclusion in all the studies included in the review made it clear that the participants did not have risk of convulsions.

In the studies analyzed in this review, the small number of patients, the not strictly double-blind application, the heterogeneity of the pathology and the methods of evaluating, could contribute in an uncertain way to errors in the results of the studies.

Outside the field of this review, many published studies have found positive results by estimating the effect of the treatment as the difference between the basal condition and the final condition of 
the patients (without randomised control group), and with this focus of research it is difficult to distinguish the treatment effect from a possible regression towards the mean (Bland 1994) and/or a possible effect of other factors such as the natural course of the disease (Hróbjartsson 2001).

\section{AUTHORS' CONCLUSIONS}

\section{Implications for practice}

The information in this review suggests that there is no strong evidence for a possible efficacy of transcranial magnetic stimulation for the treatment of depression, although these results do not exclude the possibility of benefit.

\section{Implications for research}

A randomised controlled trial multicentre study with a large number of patients (with a clear definition of drug-naïve and drug-resistant) and adequate concealment allocation would be the best way to determine the efficacy of the rTMS in depression. Given the difficulties with blinding with this technique and the subjective or unstable character of this psychopathology, the principal outcomes measures should be: readmissions, time to adjunctive treatment, time off work and/or hospital discharges. Another approach for the evaluation of this pathology could be the establishment of a cut-off point in the scales commonly used (Beck 1961, Hamilton 1960, Hamilton 1967) because in this way it avoids the arbitrary and relative of dichotomizing a percentage of reduction such $50 \%$ (Geddes 2001). It is more advisable to use selfapplied questionnaires.

There are several important points which future research of this technique should take into account. The time of duration of the possible effect studied by a large follow-up of the patients, the importance of the intensity studied by the studies which compare less than $100 \%$ motor threshold versus greater than $100 \%$ motor threshold and at the same time low frequency less than $1 \mathrm{HZ}$ versus high frequency greater than $1 \mathrm{HZ}$, as it does not seem established when inhibition appears and when excitation appears when comparing these four conditions together. Besides, the importance of localizing the point of stimulation seems to be an important subject and up until now has been little studied through controlled and randomized studies.

Other interesting comparisons for future research of this technique could include the application of the transcranial magnetic stimulation over the right dorsolateral prefrontal cortex and with low frequency (less than $1 \mathrm{HZ}$ ) versus sham TMS, and the application of this technique over the left dorsolateral prefrontal cortex with high frequency versus sham TMS; and comparison versus ECT for depressive patients without psychotic symptomatology.

\section{ACKNOWLEDGEMENTS}

The reviewers are grateful for the advice and support of Alfonso Casado, Miren Fernández, Montse Sacristán, Josep María García, Gerard Urrutia, Marta Roqué and Xavier Bonfill from the Iberoamerican Cochrane Centre (Barcelona, Spain), Ignasi Bolíbar and Aureli Tobias from the Service of Clinical Epidemiology and Public Health, Hospital de la Santa Creu i Sant Pau (Barcelona, Spain), Julio Sánchez Meca from the Universidad de Murcia (Spain), Vasili Vlassov from the Saratov State Medical University (Russia) Natalie Khin, Hugh McGuire and Rebecca Hardy from the Cochrane Collaboration Depression Neurosis and Anxiety Review Group, and the trialists who shared their data. 


\section{R E F E R E N C E S}

\section{References to studies included in this review}

Avery 1999 \{published data only\}

Avery DH, Claypoole K, Robinson L, Neumaier JF, Dunner DL, Scheele $L$, et al. Repetitive transcranial magnetic stimulation in the treatment of medication-resistant depression: preliminary data. Journal of of Nervous \& Mental Disease 1999;87(2):114-7.

\section{Berman 2000 b \{published and unpublished data\}}

Berman RM, Narasimhan M, Sanacora G, Miano AP, Hoffman RE, $\mathrm{Hu} X \mathrm{X}$, et al. A randomized clinical trial of repetitive transcranial magnetic stimulation in the treatment of major depression. Biological Psychiatry 2000;47(4):332-7.

\section{Conca 1996 \{published data only\}}

Conca A, Koppi S, König P, Swoboda E, Krecke N. Transcranial magnetic stimulation: A novel antidepressive strategy?. Neuropsychobiology 1996;34(4):204-7.

Conca A, Koppi S, Swoboda E, Krecke N, Konig P. Transcranial magnetic stimulation. A new therapeutic approach to the treatment of depressive illness. 8th Congress of the Association of European Psychiatrists, London, UK. 1996.

Koppi S, Conca A, Swoboda E, Krecke N, Koenig P. Transcranial magnetic stimulation--New antidepressive therapy? [Transkranielle magnetstimulation--Eine neue antidepressive therapie?]. Psychiatria Danubina 1997;9(2):83-8.

\section{Eschweiler 2000 \{published data only\}}

Eschweiler WG, Wegerer C, Schlotter W, SpandI W, Stevens A, Bartels $M$, et al. Left prefrontal activation predicts therapeutic effects of repetitive transcranial magnetic stimulation (rTMS) in major depression. Psychiatry Research: Neuroimaging Section 2000;99(3):161-72.

\section{García-Toro 2001 a \{published data only\}}

García-Toro M, Mayol A, Arnillas H, Capllonch I, Ibarra O, Crespí M, et al. Modest adjuntive benefit with transcranial magnetic stimulation in medication-resistant depression. Journal of Affective Disorders 2001;64(2-3):271-5.

\section{García-Toro 2001 c \{unpublished data only\}}

García-Toro M, Pascual-Leone A, Romera M, González A, Micó J, Ibarra O, et al. Prefrontal repetitive transcranial magnetic stimulation as add-on treatment in depression. Journal of Neurology, Neurosurgery and Psychiatry. 2001;71(4):546-8.

\section{George 1997 \{published data only\}}

George MS, Wassermann EM, Kimbrell TA, Little JT, Williams WE, Danielson AL, et al. Mood improvement following daily left prefrontal repetitive transcranial magnetic stimulation in patients with depression: a placebo-controlled crossover trial. American Journal of Psychiatry 1997;154(12):1752-6.

\section{George 2000 a \{published data only\}}

George MS, Nahas Z, Molloy M, Speer AM, Oliver NC, Li XB, et al. A controlled trial of daily left prefrontal cortex TMS for treating depression. Biological Psychiatry 2000;48(10):962-70.
Kozel FA, Nahas Z, deBrux C, Molloy M, Lorberbaum JP, Bohning D, et al. How coil-cortex distance relates to age, motor threshold, and antidepressant response to repetitive transcranial magnetic stimulation. Journal of Neuropsychiatry \& Clinical Neurosciences 2000;12(3):376-84.

Nahas Z, Teneback CC, Kozel A, Speer AM, DeBrux C, Molloy M, et al. Brain effects of TMS delivered over prefrontal cortex in depressed adults: Role of stimulation frequency and coil-cortex distance. Journal of Neuropsychiatry \& Clinical Neurosciences 2001;13(4):459-70.

\section{Grunhaus 2000 \{published data only\}}

Dannon PN, Dolberg OT, Schreiber S, Grunhaus L. Three and six-month outcome following courses of either ECT or rTMS in a population of severely depressed individuals - Preliminary report. Biological Psychiatry 2002;51(8):687-90.

Grunhaus L, Dannon PN, Schreiber S, Dolberg OH, Amiaz R, Ziv $R$, et al. repetitive transcranial magnetic stimulation is as effective as electroconvulsive therapy in the treatment of nondelusional major depressive disorder: an open study. Biological Psychiatry 2000;47(4):314-24.

\section{Haag 1997 \{published and unpublished data\}}

Haag C, Padberg F, Thoma H, Zwanzger P, Hampel H, Moller HJ. Rapid transcranial magnetic stimulation (rTMS) in the treatment of major depression: a randomised placebo controlled study. Pharmacopsychiatry 1997;30:173.

Padberg F, Haag C, Zwanzger P, Thoma H, Kathmann N, Stnbner S, et al. Rapid and slow transcranial magnetic stimulation are equally effective in medication-resistant depression: A placebo-controlled study. XXIst Collegium Internationale Neuro psychopharmacologicum, Glasgow, Scotland. 12th 16th July. 1998.

Padberg F, Zwanzger P, Keck ME, Toschi N, Mikhaiel P, Thoma H, et al. Repetitive transcranial magnetic stimulation in major depression: Efficacy depends on stimulation intensity. Annual Meeting of the American Psychiatric Association; May 5-10; New Orleans; LA, USA. 2001.

Padberg F, Zwanzger P, Thoma H, Kathmann N, Haag C, Greenberg B, et al. Repetitive transcranial magnetic stimulation (rTMS) in pharmocotherapy-refractory major depression: Comparative study of fast, slow and sham rTMS. Psychiatry Research 1999;88(3):163-71.

Zwanzger P, Padberg F, Moller HJ, Hampel H, Mikhaiel P, Thoma $\mathrm{H}$. Transcranial magnetic stimulation in major depression. XI World Congress of Psychiatry , Hamburg, August 6-11. 1999.

\section{Kimbrell 1999 \{published and unpublished data\}}

Kimbrell TA, Little JT, Dunn RT, Frye MA, Greenberg BD, Wassermann EM, et al. Frequency dependence of antidepressant response to left prefrontal repetitive transcranial magnetic stimulation (rTMS) as a function of baseline cerebral glucose metabolism. Biological Psychiatry 1999;46(12):1603-13. 
Kimbrell 1999b \{published data only\}

Kimbrell TA, Little JT, Dunn RT, Frye MA, Greenberg BD, Wassermann EM, et al. Frequency dependence of antidepressant response to left prefrontal repetitive transcranial magnetic stimulation (rTMS) as a function of baseline cerebral glucose metabolism. Biological Psychiatry 1999;46(12):1603-13.

\section{Klein 1999 \{published data only\}}

Klein E, Kreinin I, Chistyakov A, Koren D, Mecz L, Marmur S, et al. Therapeutic efficacy of right prefrontal slow repetitive transcranial magnetic stimulation in major depression. Archives of General Psychiatry 1999;56(4):315-20.

Kolbinger 1995 \{published data only\}

Kolbinger HM, Höflich G, Hufnagel H, Möller HJ, Kasper S. Transcranial magnetic stimulation (TMS) in the treatment of major depression - a pilot study. Human Psychopharmacology 1995;10(4):305-10.

\section{Loo 1999 \{published and unpublished data\}}

Loo C, Mitchell P, Sachdev P, McDarmont B, Parker G, Gandevia S. Double-blind controlled investigation of transcranial magnetic stimulation for the treatment of resistant major depression. American Journal of Psychiatry 1999;156(6):946-8.

Loo C, Sachdev P, Elsayed H, McDarmont B, Mitchell P, Wilkinson M, et al. Effects of a 2- to 4-week course of repetitive transcranial magnetic stimulation (rtms) on neuropsychologic functioning, electroencephalogram, and auditory threshold in depressed patients. Biological Psychiatry 2001;49(7):615-23.

\section{Mosimann In Press \{published data only\}}

Mosimann UP, Schmitt W, Berkhoff M, Müri RM, Hess CW, Fisch HU, et al. Repetitive transcranial magnetic stimulation as a putative treatment in affective disorders. In press.

\section{Padberg 1999b \{published data only\}}

Padberg F, Zwanzger P, Thoma H, Kathmann N, Haag C, Greenberg B, et al. Repetitive transcranial magnetic stimulation (rTMS) in pharmocotherapy-refractory major depression: Comparative study of fast, slow and sham rTMS. Psychiatry Research 1999;88(3):163-71.

\section{Pridmore 2000 b \{published data only\}}

Pridmore S. Substitution of rapid transcranial magnetic stimulation treatments for electroconvulsive therapy treatments in a course of electroconvulsive therapy. Depression \& Anxiety 2000;12(3):118-23.

\section{References to studies excluded from this review}

\section{Bohning 1999 \{published data only\}}

Bohning DE, Shastri A, McConnell KA, Nahas Z, Lorberbaum JP, Roberts DR, et al. A combined TMS/fMRI study of intensitydependent TMS over motor cortex. Biological Psychiatry 1999;45(4):385-94.

\section{Clark 2000 \{published data only\}}

Clark L, McTavish SF, Harmer CJ, Mills KR, Cowen PJ, Goodwin GM. Repetitive transcranial magnetic stimulation to right prefrontal cortex does not modulate the psychostimulant effects of amphetamine rTMS and amphetamine response. International Journal of Neuropsychopharmacology 2000;3(4):297-302.

\section{Conca 2000 \{published data only\}}

Conca A, Swoboda E, König P, Koppi S, Beraus W, Künz A, et al. Clinical impacts of single transcranial magnetic stimulation (STMS) as an add-on therapy in severely depressed patients under SSRI treatment. Human Psychopharmacology 2000;15(6):429-38.

\section{d'Alfonso 2000 \{published data only\}}

d'Alfonso AA, van Honk J, Hermans E, Postma A, de Haan EF. Laterality effects in selective attention to threat after repetitive transcranial magnetic stimulation at the prefrontal cortex in female subjects. Neuroscience letters 2000;280(3):195-8.

\section{Epstein 1998 \{published data only\}}

Epstein CM, Figiel GS, Mcdonald WM, Amazon-Leece J, Figiel L. Rapid rate transcranial magnetic stimulation in young and middle-aged refractory depressed patients. Psychiatric Annals 1998;28(1):36-9.

\section{Feinsod 1998 \{published data only\}}

Feinsod M, Kreinin B, Chistyakov A, Klein E. Preliminary evidence for a beneficial effect of low-frequency, repetitive transcranial magnetic stimulation in patients with major depression and schizophrenia. Depression \& Anxiety 1998;7(2):65-8.

\section{Figiel 1998 \{published data only\}}

Figiel GS, Epstein C, McDonald WM, Amazon-Leece J, Figiel L, Saldivia A, et al. The use of rapid-rate transcranial magnetic stimulation (rTMS) in refractory depressd patients. Journal of Neuropsychiatry \& Clinical Neurosciences 1998;10(1):20-5.

\section{García 1998 \{published data only\}}

García M, Micó J, Crespí M, Capllong I, Arnillas H. Estimulation magnetica transcraneal repetitiva: una nueva intervención neurobiológica buscando un lugar en psiquiatría. A propósito de cinco casos. Psiquiatria.COM [revista electrónica] 1998;2(2):21 pages.

\section{Geller 1997 \{published data only\}}

Geller V, Grisaru N, Abarbanel JM, Lemberg T, Belmaker RH. Slow magnetic stimulation of prefrontal cortex in depression and schizophrenia. Progress in Neuro-Psychopharmacology \& Biological Psychiatry 1997;21(1):105-10.

\section{George 1995 b \{published data only\}}

George MS, Wassermann EM, Williams WA, Callahan A, Ketter TA, Basser $P$, et al. Daily repetitive transcranial magnetic stimulation (rTMS) improves mood in depression. Neuroreport 1995;6(14):1853-56. 


\section{George 1996 \{published data only\}}

George MS, Wassermann EM, Williams WA, Steppel J, PascualLeone A, Basser P, et al. Changes in mood and hormone levels after rapid-rate transcranial magnetic stimulation (rTMS) of the prefrontal cortex. Journal of Neuropsychiatry \& Clinical Neurosciences 1996;8(2):172-80.

\section{George 1998 \{published data only\}}

George MS, Speer AM, Molloy M, Nahas Z, Teneback CC, Risch SC, et al. Low frequency daily left prefrontal rTMS improves mood in bipolar depression: A placebo-controlled case report. Human Psychopharmacology 1998;13(4):271-5.

\section{George 1999 \{published data only\}}

George MS, Nahas Z, Kozel FA, Goldman J, Molloy M, Oliver N. Improvement of depression following transcranial magnetic stimulation. Current Psychiatry Reports 1999;1(2):114-24.

\section{George 1999 \{published data only\}}

George MS, Lisanby SH, Sackeim HA. Transcranial magnetic stimulation: applications in neuropsychiatry. Archives of General Psychiatry 1999;56(4):300-11

\section{Grisaru 1998 \{published data only\}}

Grisaru N. TMS in mania: A controlled study. XXIst Collegium Internationale Neuro psychopharmacologicum, Glasgow, Scotland. 12th 16th July. 1998.

Grisaru N, Chudakov B, Yaroslavsky Y, Belmaker RH. Transcranial magnetic stimulation in mania: A controlled study. American Journal of Psychiatry 1998;155(11):1608-10.

\section{Habel 2001 \{published data only\}}

Habel U, Wild B, Topka H, Kircher T, Salloum JB, Schneider F. Transcranial magnetic stimulation: no effect on mood with single pulse during learned helplessness. Progress in Neuro-Psychopharmacology \& Biological Psychiatry 2001;25(3):497-506

\section{Hansen 2000 \{published data only\}}

Hansen PE. Repetitive magnetic stimulation in the treatment of depression. A review [Repetitiv transkranial magnetisk stimulation. En metode til behandling af depressioner]. Ugeskrift for Laeger 2000;162(16):2310-3.

\section{Höflich 1993 \{published data only\}}

Höflich G, Kasper S, Hufnagel A, Ruhrmann S, Möller HJ. Application of transcranial magnetic stimulation in treatment of drug-resistant major depression - a report of two cases. Human Psychopharmacology 1993;8(5):361-5

\section{Koppi 1997 DELETE \{published data only\}}

Koppi S, Conca A, Swoboda E, Krecké N, König P. Transcranial magnetic stimulation - new antidepressive therapy? [transkranielle magnetstimulation - eine neue antidepressive therapie?]. Psychiatria Danubina 1997;9(2):83-8. transcranial magnetic stimulation. Journal of Neuropsychiatry \& Clinical Neurosciences 2000;12(3):376-84.

Krystal 2000 \{published data only\}

Krystal AD, West M, Prado R, Greenside H, Zoldi S, Weiner RD. EEG effects of ECT: implications for rTMS. Depression \& Anxiety 2000;12(3):157-65.

\section{Loo 2000 \{published data only\}}

Loo CK, Taylor JL, Gandevia SC, McDarmont BN, Mitchell PB, Sachdev PS. Transcranial magnetic stimulation (TMS) in controlled treatment studies: are some "sham" forms active?. Biological Psychiatry 2000;47(4):325-31.

\section{LOo 2001 DELETE \{published data only\}}

Loo C, Sachdev P, Elsayed H, McDarmont B, Mitchell P, Wilkinson M, et al. Effects of 2- to 4-week course of repetitive transcranial magnetic stimulation (rTMS) on neuropsychologic functioning, electroencephalogram, and auditory threshold in depressed patients. Biological Psychiatry 2001;49(7):615-23.

\section{Markwort 1997 \{published data only\}}

Markwort S, Cordes P, Aldenhoff J. Transcranial magnetic stimulation as a therapeutic alternative to electroconvulsive therapy in therapy-resistant depressions [Die transkranielle magnet stimulation als behandlungs alternative zur elektrokrampf therapie bei therapieresistenten depressionen] Fortschritte der Neurologie-Psychiatrie 1997;65(12):540-9.

McConnell 2001 \{published data only\}

MCConnell KA, Nahas Z, Shastri A, Lorberbaum JP, Kozel FA, Bohning DE, et al. The transcranial magnetic stimulation motor threshold depends on the distance from coil to underlying cortex: a replication in healthy adults comparing two methods of assessing the distance to cortex. Biological Psychiatry 2001;49(5):454-9.

\section{Menkes 1999 \{published data only\}}

Menkes DL, Bodnar P, Ballesteros RA, Swenson MR. Right frontal lobe slow frequency repetitive transcranial magnetic stimulation (SF r-TMS) is an effective treatment for depression: a case-control pilot study of safety and efficacy. Journal of Neurology, Neurosurgery \& Psychiatry 1999;67(1):113-5.

\section{Mosimann 2000 \{published data only\}}

Mosimann UP, Rihs TA, Engeler J, Fisch HU, Schlaepfer TE. Mood effects of repetitive transcranial magnetic stimulation of left prefrontal cortex in healthy volunteers. Psychiatry Research 2000;94(3):251-6.

\section{Nahas 1999 \{published data only\}}

Nahas Z, Bohning DE, Molloy MA, Oustz JA, Risch SC, George MS. Safety and Feasibility of repetitive transcranial magnetic stimulation in the treatment of anxious depression in pregnancy: A case report. Journal of Clinical Psychiatry 1999;60(1):50-2.

\section{Nahas 2000 \{published data only\}}

Nahas Z, DeBrux C, Chandler V, Lorberbaum JP, Speer AM, Molloy MA, et al. Lack of significant changes on magnetic resonance scans before and after 2 weeks of daily left prefrontal
* Kozel FA, Nahas Z, deBrux C, Molloy M, Lorbergaum JP, Bohning D, et al. How coil-cortex distance relates to age, motor threshold, and antidepressant response to repetitive 
repetitive transcranial magnetic stimulation for depression. Journal of ECT 2000;16(4):380-90.

\section{Pascual-Leone 1996b \{published data only\}}

Pascual-Leone A, Catalá MD, Pascual-Leone Pascual A. Lateralized effect of rapid-rate transcranial magnetic stimulation of the prefrontal cortex on mood. Neurology 1996;46(2):499-502.

\section{Pridmore 1999a \{published data only\}}

Pridmore S. Rapid transcranial magnetic stimulation and normalization of the dexamethasone suppression test. Psychiatry \& Clinical Neurosciences 1999;53(1):33-7.

\section{Pridmore 1999b \{published data only\}}

Pridmore S, Rybak M, Turnier-Shea Y, Reid P, Bruno R, Couper D. A naturalistic study of response in melancholia to transcranial magnetic stimulation (TMS). German Journal of Psychiatry 1999;2(1):13-21.

\section{Pridmore 1999c \{published data only\}}

Pridmore S, Belmaker R. Transcranial magnetic stimulation in the treatment of psychiatric disorders. Psychiatry \& Clinical Neurosciences 1999;53(5):541-8.

\section{Pridmore $\mathbf{2 0 0 0}$ a \{published data only\}}

Pridmore S, Bruno R, Turnier-Shea Y, Reid P, Rybak M. Comparison of unlimited numbers of rapid transcranial magnetic stimulation (rTMS) and ECT treatment sessions in major depressive episode. International Journal of Neuropsychopharmacology 2000;3(4):129-34.

\section{Reid 1999 \{published data only\}}

Reid PD, Pridmore S. Dexamethasone supression test reversal in rapid transcranial magnetic stimulation-treated depression. Australian and New Zealand Journal of Psychiatry 1999;33(2):274-7.

\section{Schouten 1999 \{published data only\}}

Schouten EA, D'alfonso AA, Nolen WA, De Haan EH, Wijkstra J, Kahn RS. Small effect of rapid rate transcranial magnetic stimulation on antidepressant free outpatients with a depressive disorder. A pilot study [Beperkte effectiviteit van transcraniële magnetische stimulatie bij depressie Een oriënterend onderzoek]. Tijdschrift voor Psychiatrie 1999;41(4):233-7.

\section{Speer 1999 \{published data only\}}

Little JT, Kimbrell TA, Wassermann EM, Grafman J, Figueras S, Dunn RT, et al. Cognitive effects of 1- and 20- hertz repetitive transcranial magnetic stimulation in depression: Preliminary report. Neuropsychiatry, Neuropsychology, and Behavioral Neurology 2000;13(2):119-24.

Speer AM, Kimbrell TA, Wassemann EM, Willis MW, Post RM. Baseline absolute blood flow measured with oxygen-15 pet predicts differential antidepressants response to $1 \mathrm{hz}$ versus 20 hz rtms. 152nd Annual Meeting of the American Psychiatric Association. Washington DC, USA. 15 20th May. 1999.

Speer AM, Kimbrell TA, Wassermann EM, Repella JD, Willis MW, Herscovitch P, et al. Opposite effects of high and low frequency
rTMS on regional brain activity in depressed patients. Biological Psychiatry 2000;48(12):1133-41.

Stikhina 1999 \{published data only\}

Stikhina NY, Lyskov EB, Lomarev MP, Aleksanyan ZA, Mikhailov VO, Medvedev SV. Transcranial magnetic stimulation in neurotic depression [Transkranial'naia magnitnaia stimuliatsiia pri nevroticheskoi depressii.]. Zhurnal Nevrologii $i$ Psikhiatrii Imeni S.S. Korsakova 1999;99(10):26-9.

Szuba 2000 \{published data only\}

Szuba MP, O'Reardon JP, Evans DL. Psysiological effects of electroconvulsive therapy and transcranial magnetic stimulation in major depression. Depression \& Anxiety 2000;12(3):170-7.

\section{Teneback 1999 \{published data only\}}

Teneback C, Nahas Z, Speer AM, Molloy M, Stallings LE, Spicer KM, et al. Changes in prefrontal cortex and paralimbic activity in depression following two weeks of daily left prefrontal TMS. Journal of Neuropsychiatry and Clinical Neurosciences 1999;11(4):426-35.

Tormos 1999 \{published data only\}

Tormos JM, Catalá MD, Pascual-Leone A. Transcranial magnetic stimulation [Estimulación magnética transcraneal]. Revista de Neurologia 1999;29(2):165-71.

Triggs 1999 \{published data only\}

Triggs WJ, McCoy KJM, Greer R, Rossi F, Bowers D, Kortenkamp $S$, et al. Effects of left frontal transcranial magnetic stimulation on depressed mood, cognition, and corticomotor threshold. Biological Psychiatry 1999;45(11):1440-6.

\section{Turnier-Shea 1999 \{published data only\}}

Turnier-Shea Y, Rybak M, Reid P, Pridmore S. Update on psychotropic medication used concurrently with transcranial magnetic stimulation. German Journal of Psychiatry 1999;2(2):46-59.

\section{Walter 2001 \{published data only\}}

Walter G, Tormos JM, Israel JA, Pascual-Leone A. Transcranial magnetic stimulation in young persons: a review of known cases. Journal of Child \& Adolescent Psychopharmacology 2001;11(1):69-75.

\section{Zheng 2000 \{published data only\}}

* Zheng XM. Regional cerebral blood flow changes in drugresistant depressed patients following treatment with transcranial magnetic stimulation: a statistical parametric mapping analysis. Psychiatry Research: Neuroimaging 2000;100(2):75-80.

\section{References to studies awaiting assessment}

Pascual-Leone 1996 \{published data only\}

Pascual-Leone A, Rubio B, Pallardo F, Catala MD. Rapidrate transcranial magnetic stimulation of left dorsolateral prefrontal cortex in drug-resistant depression. Lancet 1996;347(9022):233-7. 
Speer 2000 \{published data only\}

Speer AS, Kimbrell TA, Wassermann EM, Repella JD, Willis MW, Herscovitch P, et al. Opposite effects of high and low frequency rTMS on regional brain activity in depressed patients. Biological Psychiatry 2000;48(12):1133-41.

\section{References to ongoing studies}

Adsersen-1 \{unpublished data only\}

Adsersen. The Avery-George-Hotzheimer database of rTMS depression studies. http://www.ists.unibe.ch/ists/ TMSAvery.htm.

\section{Avery-1 \{unpublished data only\}}

Avery. The Avery-George-Hotzheimer database of rTMS depression studies. http://www.ists.unibe.ch/ists/ TMSAvery.htm.

\section{D'Alfonso-1 \{unpublished data only\}}

D'Alfonso. The Avery-George-Hotzheimer database of rTMS depression studies. http://www.ists.unibe.ch/ists/ TMSAvery.htm.

\section{Ebmeier-1 \{unpublished data only\}}

Ebmeier. The Avery-George-Hotzheimer database of rTMS depression studies. http://www.ists.unibe.ch/ists/ TMSAvery.htm.

\section{Eckert-1 \{unpublished data only\}}

Eckert. The Avery-George-Hotzheimer database of rTMS depression studies. http://www.ists.unibe.ch/ists/ TMSAvery.htm.

\section{Greenberg-1 \{unpublished data only\}}

Greenberg. The Avery-George-Hotzheimer database of rTMS depression studies. http://www.ists.unibe.ch/ists/ TMSAvery.htm.

\section{McLoughlin-1 \{unpublished data only\}}

McLoughlin. The Avery-George-Hotzheimer database of rTMS depression studies. http://www.ists.unibe.ch/ists/ TMSAvery.htm.

\section{Paradiso-1 \{unpublished data only\}}

Paradiso. The Avery-George-Hotzheimer database of rTMS depression studies. http://www.ists.unibe.ch/ists/ TMSAvery.htm.

\section{Pascual-Leone-1 \{unpublished data only\}}

Pascual-Leone. The Avery-George-Hotzheimer database of rTMS depression studies. http://www.ists.unibe.ch/ists/ TMSAvery.htm.

\section{Pascual-Leone-2 \{unpublished data only\}}

Pascual-Leone. The Avery-George-Hotzheimer database of rTMS depression studies. http://www.ists.unibe.ch/ists/ TMSAvery.htm.
Sackeim-1 \{unpublished data only\}

Sackeim. The Avery-George-Hotzheimer database of rTMS depression studies. http://www.ists.unibe.ch/ists/ TMSAvery.htm.

\section{Schaepfer-1 \{unpublished data only\}}

Schaepfer. The Avery-George-Hotzheimer database of rTMS depression studies. http://www.ists.unibe.ch/ists/ TMSAvery.htm.

\section{Shajahan-1 \{unpublished data only\}}

Shajahan P. The treatment of partial remission in depression using transcranial magnetic stimulation (TMS): Open pilot trial followed by randomised placebo controlled cross-over study. National Research Register 2000, issue 3.

Szuba-1 \{unpublished data only\}

Szuba. The Avery-George-Hotzheimer database of rTMS depression studies. http://www.ists.unibe.ch/ists/ TMSAvery.htm.

\section{Weber-1 \{unpublished data only\}}

Weber. The Avery-George-Hotzheimer database of rTMS depression studies. http://www.ists.unibe.ch/ists/ TMSAvery.htm.

Woodruff-1 \{unpublished data only\}

Woodruff P. Cost effectiveness of transcranial magnetic stimulation and electro-convulsive treatment in severe depression (TRANSECT). National Research Register 2000, issue 3.

\section{Additional references}

\section{Andrews 1999}

Andrews $\mathrm{G}$. Randomised controlled trials in psychiatry: important but poorly accepted. BMJ 1999;319:562-4.

\section{APA 1994}

American Psychiatric Association. Diagnostic and Statistical Manual of Mental Disorders (dsm-iv). 4th Edition. Washington, DC: American Psychiatric Association, 1994.

\section{Barker 1985}

Barker AT, Jalinous R, Freeston H. Non-invasive stimulation of the human motor cortex. Lancet. 1985;1:1106-7.

\section{Beck 1961}

Beck AT, Ward CH, Mendelson M, Mock J, Erbaugh J. An Inventory for measuring depression. Archives of general psychiatry 1961;4:53-63.

\section{Berger 1999}

Berger VW, Exner DV. Detecting selection bias in randomized clinical trials. Controlled Clinical Trials 1999;20:319-27.

\section{Bland 1994}

Bland JM, Altman DG. Some examples of regression towards the mean. BMJ 1994;309:780. 


\section{Bonfill 2001}

Bonfill X. Ensayos clínicos en intervenciones no farmacológicas. Barcelona: Fundación Dr. Antonio Esteve, 2001.

\section{Casado 1999}

Casado A, Prieto L, Alonso J. The size of the effect of the difference between two means: statistically significant or clinically relevant? [El tamaño del efecto de la diferencia entre dos medias: ¿estadísticamente significativo o clínicamente relevante?]. Medicina Clinica 1999;112(15):584-8.

\section{Chalmers 1992}

Chalmers I, Dickersin K, Chalmers TC. Getting to grips with Archie Cochrane's agenda. BMJ 1992;305:786-8.

\section{Clarke 2001}

Clarke M, Oxman AD. Cochrane Reviewers Handbook. Oxford: Update Software, 2001.

\section{Cohrs 1998}

Cohrs S, Tergau F, Riech S, Kastner S, Paulus W, Ziemann U, et al. High-frequency repetitive transcranial magnetic stimulation delays rapid eye movement sleep. Neuroreport 1998;9(15):3439-43.

\section{Collier 1995}

Collier J. Confusion over use of placebos in clinical trials. BMJ 1995;311:821-2.

\section{Cracco 1999}

Cracco RQ, Cracco JB, Maccabee PJ, Amassian VE. Cerebral function revealed by transcranial magnetic stimulation. Journal of Neuroscience Methods 1999;86(2):209-19.

\section{Davis 1976}

Davis CE. The effect of regression to the mean in epidemiologic and clinical studies. American Journal of Epidemiology 1976;104(5):493-8.

\section{Day 2000}

Day SJ. Blinding in clinical trials and other studies. BMJ 2000;321(7259):504.

\section{Freemantle 2001}

Freemantle N. Interpreting the results of secondary end points and subgroup analyses in clinical trials: should we lock the crazy aunt in the attic?. BMJ 2001;322(7292):989-91.

\section{Geddes 2001}

Geddes JR, Freemantle N, Mason J, Eccles MP, Boynton J. Selective serotonin reuptake inhibitors (SSRIs) for depression (Cochrane Review). Cochrane Database of Systematic Reviews 2001, Issue 3.

\section{Grafman 1999}

Grafman J, Wassermann E. Transcranial magnetic stimulation can measure and modulate learning and memory. Neuropsychologia 1999;37(2):159-67.

\section{Guallar 1997}

Guallar E, Jiménez FJ, García-Alonso F, Bakke OM. Regression to the median in research and clinical practice [La regresión a la media en la investigación y práctica clínica]. Medicina Clinica 1997;109(1):23-6.

\section{Hallett 2000}

Hallett M. Transcranial magnetic stimulation and the human brain. Nature 2000;406(6792):147-50.

\section{Hamilton 1960}

Hamilton M. A rating scale for depression. Journal of Neurology, Neurosurgery \& Psychiatry 1960;23:56-62.

\section{Hamilton 1967}

Hamilton M. Development of a rating scale for primary depressive illness. British Journal of Social \& Clinical Psychology 1967;6(4):278-96.

\section{Hasey 2000}

Hasey G, Joffe R, Ivanski C. Managing neuropsychiatric disease with transcranial magnetic stimulation. CMAJ 2000;162(1):79-80.

\section{Hotopf 1999}

Hotopf M, Churchill R, Lewis G. Pragmatic randomised controlled trials in psychiatry. British Journal of Psychiatry 1999;175:217-23.

\section{Hróbjartsson 2001}

Hróbjartsson A, Gotzsche PC. Is the placebo powerless?. New England Journal of Medicine 2001;344(21):1594-602.

\section{Jadad 1998}

Jadad AR. Randomised controlled trials. London: BMJ Books, 1998.

\section{Ji 1998}

Ji RR, Schlaepfer TE, Aizenman CD, Epstein CM, Qiu D, Huang JC, et al. Repetitive transcranial magnetic stimulation activates specific regions in the rat brain. Proceedings of the National Academy of Sciences of the United States of America 1998;95(26):15635-40

\section{Jones 1996}

Jones B, Jarvis P, Lewis JA, Ebbutt AF. Trials of assess equivalence: the importance of rigorous method. $B M J$ 1996;313(7056):36-9.

\section{Juckel 1999}

Juckel G, Mendlin A, Jacobs BL. Electrical stimulation of rat medial prefrontal cortex enhances forebrain serotonin output: implications for electroconvulsive therapy and transcranial magnetic stimulation in depression. Neuropsychopharmacology 1999;21(3):391-8.

\section{Kujirai 1993}

Kujirai T. Corticocortical inhibition in human motor cortex. Journal of Physiology 1993;471:501-19. 


\section{Laporte 1994}

Laporte JR, Figueras A. Placebo effects in psychiatry. Lancet 1994;344(8931):1206-9.

\section{Lisanby 2000}

Lisanby SH, Luber B, Perera T, Sackeim HA. Transcranial magnetic stimulation: applications in basic neuroscience and neuropsychopharmacology. International Journal of Neuropsychopharmacology 2000;3:259-73.

\section{Moher 1995}

Moher D, Jadad A, Nichol G, Penman M, Tugwell T, Walsh S. Assessing the quality of randomized controlled trials: an annotated bibliography of scales and checklists. Controlled Clinical Trials 1995;16(1):62-73.

\section{Pascual-Leone 1998}

Pascual-Leone A, Tornos JM, Keenan J, Tarazona F, Canete C, Catala MD. Study and modulation of human cortical excitability with transcranial magnetic stimulation. Journal of Clinical Neurophysiology 1998;95(4):333-43.

\section{Post 1998}

Post RM, Denicoff KD, Frye MA, Dunn RT, Leverich GS, Osuch E, et al. A history of the use of anticonvulsants as mood stabilizers in the last two decades of the 20th century. Neuropsychology 1998;38(3):152-66.

\section{Post 1999}

Post RM, Kimbrell TA, McCann UD, Dunn RT, Osuch EA Speer AM, et al. Repetitive transcranial magnetic stimulation as a neuropsychiatric tool: present status and future potential. Journal of ECT 1999;15(1):39-59.

\section{Rosenberg 2000}

Rosenberg R. Outcome measures of antidepressive therapy. Acta Psychiatrica Scandinavica, Supplementum 2000;402:41-4.

\section{Ruohonen 2000}

Ruohonen J, Ollikainen M, Nikouline V, Virtanen J, Ilmoniemi RJ. Coil desing for real and sham transcranial magnetic stimulation. IEEE Transactions on Biomedical Engineering 2000;47(2):145-8.

\section{Schulz 1995}

Schulz KF, Chalmers I, Hayes RJ, Altman DG. Empirical evidence of bias: dimensions of methodological quality associated with estimates of treatment effects in controlled trials. JAMA 1995;273(5):408-12.

\section{Steele 2000}

Steele JD, Glabus MF, Shajahan PM, Ebmeier KP. Increased cortical inhibition in depression: a prolonged silent period with transcranial magnetic stimulation (TMS). Psychological Madicine 2000;30(3):565-70.

\section{Streiner 1998}

Streiner DL, Joffe R. The adequacy of reporting randomized, controlled trials in the evaluation of antidepressants. Canadian Journal of Psychiatry 1998;43(10):1026-30.

\section{Thomas 1987}

Thomas KB. General practice consultations: is there any point in being positive?. BMJ 1987;294(6581):1200-2.

\section{Wells 1999}

Wells KB. Treatment research at the crossroads: the scientific interface of clinical trials and effectiveness research. American Journal of Psychiatry 1999;156(1):5-10.

\section{WHO 1993}

World Health Organisation. The Tenth Revision of the International Classification of Diseases and Related Health Problems (ICD-10). 10th Edition. Geneva: World Health Organisation, 1993.

\section{Zyss 1999}

Zyss T, Mamczarz J, Vetulani J. The influence of rapid-rate transcranial magnetic stimulation (rTMS) parameters on rTMS effects in Porsolt's forced swimming test. International Journal of Neuropsychopharmacology 1999;2:31-4.

* Indicates the major publication for the study

\section{CHARACTERISTICS OF STUDIES}

Characteristics of included studies [ordered by study ID]

Avery 1999

\begin{tabular}{ll} 
Methods & $\begin{array}{l}\text { Randomised } \\
\text { double-blind } \\
\text { Placebo control } \\
\text { Parallel trial } \\
2 \text { weeks treatment } \\
2 \text { weeks follow-up }\end{array}$ \\
\hline Participants & $\begin{array}{l}\text { Included: } \\
\text { Outpatients. Medication-resistant. DSM-IV criteria for major depression or bipolar disorder (depressed } \\
\text { phase) } \\
\text { Patients had to have a score of at least } 20 \text { on the SIGH-SAD and be right-handed by the Lateral Domi- } \\
\text { nance Examination. }\end{array}$ \\
\hline
\end{tabular}


Avery 1999 (Continued)

Excluded: patients with metal in the body, cardiac pacemaker or any other implanted electronic device, a history of head injury associated with loss of consciousness, brain surgery, epilepsy, or labile or hypertensive blood pressure, other major psychiatric or medical illnesses, or active suicidal intent or plan.

Number randomised: 6

Mean age: 44.5 (8.48)

Men: 1

Women: 5

0 Withdrawals

Patients taking stable ineffective doses of medications for at least 6 weeks continued on the same dose during the study

Patiens on no medication continued on no medication.

Interventions

rTMS ( $10 \mathrm{~Hz}$ at $80 \%$ motor threshold, 10000 total pulses, 20 trains per session, 5" train duration) over the left dorsolateral prefrontal cortex +- current medication vs Sham TMS +- current medication Coil: fig. 8

\begin{tabular}{ll}
\hline Outcomes & Hamilton Depression Rating Scale-21 item \\
& Beck Depression Inventory \\
SIGH-SAD & Global Improvement \\
& Neuropsychological tests
\end{tabular}

\section{Notes}

\section{Risk of bias}

\begin{tabular}{lll}
\hline Bias & Authors' judgement & Support for judgement \\
\hline $\begin{array}{l}\text { Allocation concealment } \\
\text { (selection bias) }\end{array}$ & Unclear risk & B - Unclear \\
\hline
\end{tabular}

Berman 2000 b

\begin{tabular}{ll}
\hline Methods & $\begin{array}{l}\text { Randomised } \\
\text { double-blind placebo control } \\
\text { Parallel trial } \\
2 \text { weeks treatment }\end{array}$ \\
\hline Participants & Included: \\
& Inpatients and outpatients \\
& DSM-IV criteria for major depressive episode. Patients with comorbid psychiatric diagnosis (provided \\
& that the onset ocurred after the development of major depression and the symptoms of major depres- \\
& sion were most prominent by consensus of two research psychiatrists) were included. \\
& Excluded: \\
& Diagnosis of substance abuse, pregnancy, neurological illness (seizures or head trauma), \\
& epilectic predisposition. \\
& Number randomised: 20 \\
& Mean age: 42.3 (10.1) \\
& Men: 14 \\
& Women: 6 \\
& 3 Withdrawals \\
& Two patients were on medications (amlodipine, lisinopril, glyburide, digoxin, warfarin sodium). \\
& Patients were free of psychotropic drugs for the week prior. \\
& For inpatients were allowed chloral hydrate for severe insomnia. \\
&
\end{tabular}


Berman 2000 b (Continued)

Interventions
rTMS ( $20 \mathrm{~Hz}$ at $80 \%$ motor threshold, 4000 total pulses, 20 trains per session, 2 " train duration) over the left dorsolateral prefrontal cortex +- medication vs Sham TMS +- medication

Coil: fig. 8

\begin{tabular}{ll}
\hline Outcomes & $\begin{array}{l}\text { Hamilton Depression Rating Scale-25 item } \\
\text { Beck Depression Inventory } \\
\text { Hamilton Anxiety Scale } \\
\text { Side effects checklist }\end{array}$ \\
\hline Notes & $\begin{array}{l}\text { Patients were assessed daily by a blinded research assistant } \\
3 \text { Withdrawals analysed by last observation carried forward. } \\
\text { Patients guessed their blind accurately in } 10 \text { out of } 15(67 \%) \text { assessed cases. Raters guessed blind cor- } \\
\text { rectly in } 12 \text { out of } 15(80 \%) \text { cases. }\end{array}$
\end{tabular}

\section{Risk of bias}

\begin{tabular}{lll}
\hline Bias & Authors' judgement & Support for judgement \\
\hline $\begin{array}{l}\text { Allocation concealment } \\
\text { (selection bias) }\end{array}$ & Unclear risk & B - Unclear \\
\hline
\end{tabular}

\section{Conca 1996}

\begin{tabular}{|c|c|c|}
\hline Methods & \multicolumn{2}{|l|}{$\begin{array}{l}\text { Randomised } \\
\text { single-blind } \\
\text { parallel trial }\end{array}$} \\
\hline Participants & \multicolumn{2}{|c|}{$\begin{array}{l}\text { Included: } \\
\text { inpatients. } \\
\text { DSM-III-R criteria for major depression with either a severe single episode or severe recurrent without } \\
\text { seasonal pattern, both without psychotic features. } \\
\text { Number randomised: } 24 \\
\text { Mean age: } \\
\text { TMS group: } 43.67(12.14) \\
\text { Drugs group: } 41.75(11.83) \\
\text { Men: } 6 \\
\text { Women: } 18\end{array}$} \\
\hline Interventions & \multicolumn{2}{|c|}{$\begin{array}{l}\text { rTMS ( } 1.9 \text { T) over Fp1, Fp2, F3, F4, T3, T4, P3, P4 + standard antidepressive medication vs antidepressive } \\
\text { medication } \\
\text { Coil: circular }\end{array}$} \\
\hline Outcomes & \multicolumn{2}{|c|}{ Hamilton Depression Rating Scale-24 } \\
\hline Notes & \multicolumn{2}{|c|}{$\begin{array}{l}\text { We have not used this study for quantitative analysis because we can not differentiate the placebo ef- } \\
\text { fect of rTMS treatment }\end{array}$} \\
\hline \multicolumn{3}{|l|}{ Risk of bias } \\
\hline Bias & Authors' judgement & Support for judgement \\
\hline $\begin{array}{l}\text { Allocation concealment } \\
\text { (selection bias) }\end{array}$ & Unclear risk & B - Unclear \\
\hline
\end{tabular}


Eschweiler 2000

\begin{tabular}{|c|c|c|}
\hline Methods & \multicolumn{2}{|l|}{$\begin{array}{l}\text { Randomised } \\
\text { Double-blind } \\
\text { Placebo Control } \\
\text { Crossover trial } \\
4 \text { weeks duration }\end{array}$} \\
\hline Participants & \multicolumn{2}{|c|}{$\begin{array}{l}\text { Included: } \\
\text { Hight-handed patients on continuous antidepressant medication. } \\
\text { DSM-IV criteria for major depression episode. } \\
\text { Number Randomised: } 12 \\
\text { Male: } 4 \\
\text { Female: } 8 \\
\text { Age: } 57 \text { ( } 8 \text { ) } \\
3 \text { Withdrawals }\end{array}$} \\
\hline Interventions & \multicolumn{2}{|c|}{$\begin{array}{l}\text { rTMS }(10 \mathrm{~Hz} \text { at } 90 \% \text { motor threshold, } 20 \text { trains per session, } 10 \text { " duration) over the left dorsolateral pre- } \\
\text { frontal cortex + current antidepressive medication vs Sham TMS + current antidepressive medication } \\
\text { Coil: fig. } 8 \\
\text { (two patients were on treatment in the both phases) }\end{array}$} \\
\hline Outcomes & \multicolumn{2}{|c|}{$\begin{array}{l}\text { Hamilton Depression Rating Scale- } 21 \text { items } \\
\text { Beck Depression Inventory }\end{array}$} \\
\hline Notes & \multicolumn{2}{|c|}{$\begin{array}{l}\text { We have used only the first phase of the trial } \\
1 \text { week treatment }+1 \text { week follow up after treatment. } \\
3 \text { Withdrawals analysed by last observation carried forward. }\end{array}$} \\
\hline \multicolumn{3}{|l|}{ Risk of bias } \\
\hline Bias & Authors' judgement & Support for judgement \\
\hline $\begin{array}{l}\text { Allocation concealment } \\
\text { (selection bias) }\end{array}$ & Unclear risk & B - Unclear \\
\hline
\end{tabular}

García-Toro 2001 a

\begin{tabular}{ll}
\hline Methods & Randomised \\
double-blind & placebo control \\
& Parallel trial \\
& 2 week treatment \\
& 2 week follow-up \\
In a second phase of the study there were a 2 week treatment \& 2 week follow-up for all the patients in \\
a open trial. \\
Included: \\
Medication-resistant. \\
> 18 age, DSM-IV criteria for unipolar major depression. Patients should also have taken the same anti- \\
depressant medication during the last 6 weeks prior to inclusion and they accepted to continue doing \\
so during all the study. \\
Exclusion: \\
previous seizures or neurosurgery, current serious or uncontrolled medical illness, patients with pace- \\
makers or hearing aids, pregnant, and high suicidal risk. \\
Number randomised. 40 \\
Mean age: 51.5 (15.9) real \\
Mean age: 50.0 (11.0) sham
\end{tabular}


García-Toro 2001 a (Continued)

Men: 20

Women: 15

5 withdrawals: 2 in the sham group and 3 in the treatment group.

Interventions $\quad$ rTMS $(20 \mathrm{~Hz}$ at $90 \%$ motor threshold) over the left prefrontal cortex + their pharmacological treatment vs Sham TMS + their pharmacological treatment

Coil: fig. 8

$\begin{array}{ll}\text { Outcomes } & \text { Hamilton Depression Rating Scale-21 item } \\ & \text { Hamilton Anxiety Rating Scale } \\ & \text { Clinical Global Impression } \\ & \text { Beck Depression Inventory. }\end{array}$

Notes

The dropped patients were excluded from analysis.

We have not used the second phase (open phase) of this trial.

\section{Risk of bias}

\begin{tabular}{lll}
\hline Bias & Authors' judgement & Support for judgement \\
\hline $\begin{array}{l}\text { Allocation concealment } \\
\text { (selection bias) }\end{array}$ & Unclear risk & B - Unclear \\
\hline
\end{tabular}

García-Toro 2001 c

\begin{tabular}{|c|c|}
\hline Methods & $\begin{array}{l}\text { Randomised } \\
\text { double-blind } \\
\text { placebo control } \\
\text { Parallel trial } \\
2 \text { week treatment } \\
2 \text { weeks follow-up }\end{array}$ \\
\hline Participants & $\begin{array}{l}\text { Included: } \\
\text { Inpatients and outpatients } \\
\text { >18 age, without sertraline treatment for the current episode. } \\
\text { DSM-IV criteria for major depression. } \\
\text { Excluded: } \\
\text { Personal or family history of seizures, past neurolosurgical procedures, implanted pacemaker, inner } \\
\text { ear prothesis, pregnancy, medication pumps, unstable medical conditions, and high suicidal risk. } \\
\text { Number randomised: } 28 \\
\text { Mean age and gender of non dropped patiens: } \\
\text { Mean age: } 43.2 \text { (13.1) real } \\
\text { Mean age: } 45.0 \text { (18.3) sham } \\
\text { Men: } 10 \\
\text { Women: } 12 \\
6 \text { withdrawals ( } 3 \text { each group) } \\
2 \text { left-handed. } \\
\text { All } 28 \text { patients, except } 2, \text { were taking benzodiazepines at the time of entry into the study. These were } \\
\text { kept unchanged. }\end{array}$ \\
\hline Interventions & $\begin{array}{l}\text { rTMS }(20 \mathrm{~Hz} \text { at } 90 \% \text { motor threshold, } 12000 \text { total pulses, } 30 \text { trains per session, } 2 \text { " train duration) over } \\
\text { the left dorsolateral prefrontal cortex + sertraline +- benzo. vs Sham TMS + sertraline +- benzo. } \\
\text { Coil: fig } 8 \\
\text { Wash-up period of } 1 \text { week off the medications prior the treatment }\end{array}$ \\
\hline Outcomes & $\begin{array}{l}\text { Hamilton Depression Rating Scale-21 item } \\
\text { Global Clinical Inventory }\end{array}$ \\
\hline
\end{tabular}


García-Toro 2001 c (Continued)

Beck Depression Inventory

Notes At the end of each sessions patients were asked about possible secondary effects.

The dropped patients were excluded from analysis.

\section{Risk of bias}

\begin{tabular}{lll}
\hline Bias & Authors' judgement & Support for judgement \\
\hline $\begin{array}{l}\text { Allocation concealment } \\
\text { (selection bias) }\end{array}$ & Unclear risk & B - Unclear \\
\hline
\end{tabular}

\section{George 1997}

\begin{tabular}{ll}
\hline Methods & Randomised \\
double-blind & Placebo control \\
& Crossover trial \\
& 2week treatment \\
\hline Participants & Included: \\
& Outpatients \\
& Schedule for Affective Disorders and Schizophrenia, \\
& Structured Clinical Interview for DSM-IV criteria for current major depressive disorder (11 recurrent \\
& unipolar depression and 1 bipolar II disorder) \\
& Excluded: \\
& Patients with pacemakers, history of seizures, major head trauma, HIV, and drug abuse. \\
& Number randomised: 12 \\
& Mean age: 41.8 (12.4) \\
& Men: 1 \\
& Women: 11 \\
& O Withdrawals \\
& The antidepressant medication regimens of nine subjects were tapered. \\
& Three patients continued with their medication regimen
\end{tabular}

Interventions

rTMS ( $20 \mathrm{~Hz}$ at $80 \%$ motor threshold, 8000 total pulses, 20 trains per session, 2 " train duration) over the left prefrontal cortex +- medication vs Sham TMS +- medication

Coil: fig. 8

\begin{tabular}{ll}
\hline Outcomes & Hamilton Depression Rating Scale \\
\hline Notes & $\begin{array}{l}\text { We have used only the first phase of the trial } \\
2 \text { weeks of treatment }\end{array}$
\end{tabular}

2 weeks of treatment

\section{Risk of bias}

\begin{tabular}{lll}
\hline Bias & Authors' judgement & Support for judgement \\
\hline $\begin{array}{l}\text { Allocation concealment } \\
\text { (selection bias) }\end{array}$ & Unclear risk & B - Unclear \\
\hline
\end{tabular}

George 2000 a

Methods Randomised


George 2000 a (Continued)

\author{
double-masked \\ placebo control \\ Parallel trial \\ 2 week treatment
}

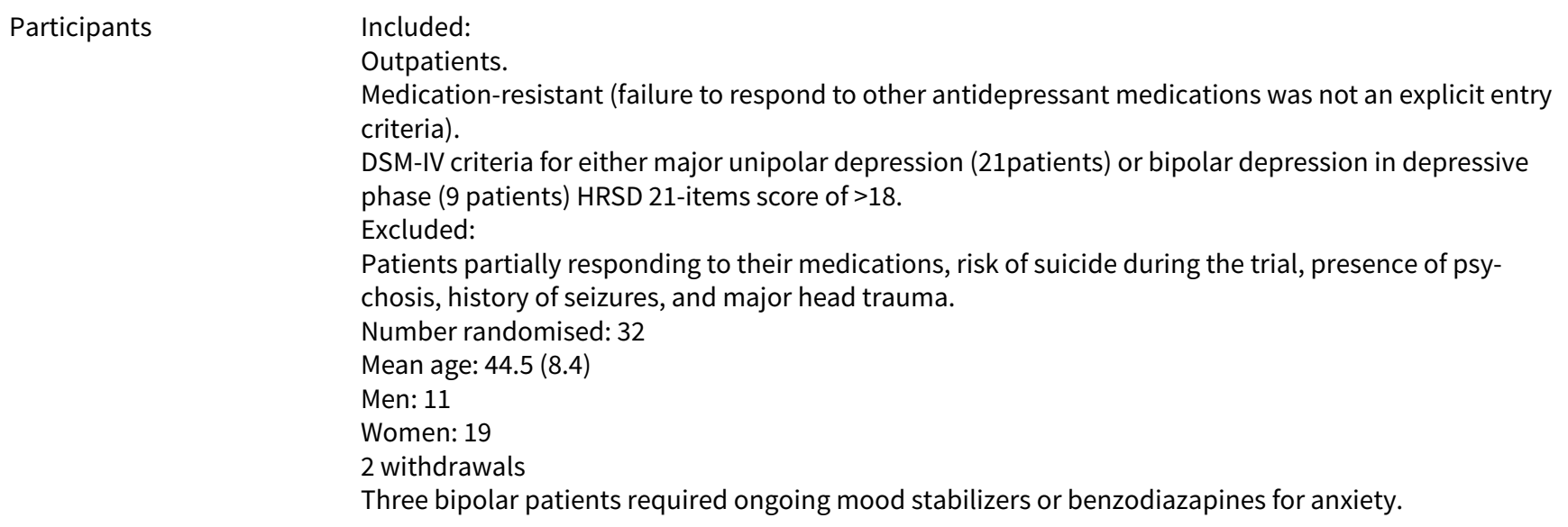

$\begin{array}{ll}\text { Outcomes } & \text { Hamilton Depression Rating Scale-21 item } \\ \text { Beck Depression Inventory } \\ \text { Hamilton Anxiety Rating Scale } \\ \text { Clinical global Improvement } \\ \text { Folstein Mini-Mental State Exam }\end{array}$

Notes The dropped patients were excluded from analysis.

\title{
Risk of bias
}

\begin{tabular}{lll}
\hline Bias & Authors' judgement & Support for judgement \\
\hline $\begin{array}{l}\text { Allocation concealment } \\
\text { (selection bias) }\end{array}$ & Unclear risk & B - Unclear \\
\hline
\end{tabular}

Grunhaus 2000

\begin{tabular}{ll}
\hline Methods & Randomised \\
& Open \\
& Parallel trial \\
& 4 week treatment \\
\hline Participants & Included: \\
Inpatients and outpatients. & Medication-resistant and/or diagnosis of psychotic major depressive disorder. \\
& $>18$ age, DSM-IV criteria for major depressive disorder. \\
& Hamilton Rating Scale for Depression $>18$. \\
& Excluded: \\
& History of seizure, medical, neurological, or neurosurgical disorder, patients with additional axis-I. \\
& Number randomized: 40 \\
& Mean age: $58.4(15.7)$ rTMS \\
& Mean age: $63.6(15.0)$ ETC
\end{tabular}


Grunhaus 2000 (Continued)

Men: 14

Woman 26

0 Withdrawals

All psychiatric medications were discontinued before the administration of rTMS. clonazepan was started in all patients to decrease anxiety, severe insomnia and have an additional protective element regarding seizures

Interventions

rTMS ( $10 \mathrm{~Hz}$ at $90 \%$ motor threshold, 8000 total pulses, 20 trains per session, 2 " train duration) over the left dorsolateral prefrontal cortex vs ECT (performed according to standard protocols).

Coil: fig. 8

$\begin{array}{ll}\text { Outcomes } & \text { Hamilton Depression Rating Scale-17 item } \\ \text { Brief Psychiatric Rating Scale } \\ \text { Global Depression Scale } \\ \text { Global Assessment of Function Scale } \\ \text { Pittsburgh Sleep Quality Index } \\ \text { Mini Mental State Examination }\end{array}$

Notes $\quad$ All ratings were performed by the same research assistant (not blind)

The first eight patients were treated with a total of 400 magnetic pulses per treatment day. The final 12 patients were treated with a total of 1200 magnetic pulses per treatment day.

\section{Risk of bias}

\begin{tabular}{lll}
\hline Bias & Authors' judgement & Support for judgement \\
\hline $\begin{array}{l}\text { Allocation concealment } \\
\text { (selection bias) }\end{array}$ & Unclear risk & B - Unclear \\
\hline
\end{tabular}

Haag 1997

\begin{tabular}{ll}
\hline Methods & $\begin{array}{l}\text { Randomised } \\
\text { double-blind } \\
\text { placebo control } \\
\text { Parallel trial } \\
1 \text { week treatment }\end{array}$ \\
\hline Participants & Included: \\
& Redication-resistant \\
& DSM-handed criteria for major depressive disorder \\
& Excluded: \\
& Organic brain disorders, pacemakers, mobile metal implants or implanted medication pumps \\
& Number randomised: 18 \\
& mean age: 51.2 (16.1) \\
& Men: 7 \\
& Women: 11 \\
& 0 withdrawal \\
& In 15 patients, the last antidepressant was kept at a stable dose.
\end{tabular}

Interventions

rTMS ( $10 \mathrm{~Hz}$ at $90 \%$ motor threshold, 1250 total pulses, 5 trains per session, 5 " train duration) over the left dorsolateral prefrontal cortex +- current medication vs rTMS $(0.3 \mathrm{~Hz}$ at $90 \%$ motor threshold, 10 trains per session) over the left dorsolateral prefrontal cortex +- current medication vs Sham TMS +current medication

Coil: fig. 8 
Haag 1997 (Continued)

Montgomery-Asberg Depression Rating Scale

Adjective Mood and Depression Scales

Neuropsychological tasks

Notes

\section{Risk of bias}

\begin{tabular}{lll}
\hline Bias & Authors' judgement & Support for judgement \\
\hline $\begin{array}{l}\text { Allocation concealment } \\
\text { (selection bias) }\end{array}$ & Unclear risk & B - Unclear \\
\hline
\end{tabular}

Kimbrell 1999

\begin{tabular}{|c|c|}
\hline Methods & $\begin{array}{l}\text { Randomised } \\
\text { double-blind } \\
\text { Placebo control } \\
\text { Crossover order } \\
4 \text { week treatment }\end{array}$ \\
\hline Participants & $\begin{array}{l}\text { Included: } \\
\text { SCID interview and meeting DSM-IV criteria for major depression } \\
\text { Excluded: } \\
\text { No reported } \\
\text { Number randomised: } 13 \\
\text { Mean age: } 42.46 \text { (15) } \\
\text { Men: } 6 \\
\text { Women: } 7 \\
0 \text { withdrawals } \\
\text { First order: } \\
5 \text { patients to I Hz } \\
5 \text { patients to } 20 \mathrm{~Hz} \\
3 \text { patients to Sham TMS } \\
\text { Diagnosis: } \\
9 \text { medication free unipolar patients } \\
1 \text { bipolar II (on lithium) } \\
3 \text { bipolar I (on lithium and carmabamazepine, on lithium and lamotrigine, and medication free, respec- } \\
\text { tively) } \\
\text { Bipolar patients who had relapsed during their ongoing mood stabilizer treatment with a major de- } \\
\text { pressive episode were allowed to remain on these medications to prevent a possible manic exacerba- } \\
\text { tion. }\end{array}$ \\
\hline
\end{tabular}

Interventions

rTMS $(20 \mathrm{~Hz}$ at $80 \%$ motor threshold, 8000 total pulses, 20 trains per session, 2" train duration) over the left prefrontal cortex +- medication vs rTMS $(1 \mathrm{~Hz}$ at $80 \%$ motor threshold, 8000 total pulses, 20 trains per session, 2" train duration) over the left prefrontal cortex +- medication vs Sham TMS +- medication Coil: fig. 8

\begin{tabular}{ll}
\hline Outcomes & Hamilton Depression Rating Scale \\
Beck Depression Inventory
\end{tabular}

Notes We have used only the first treatment condition of the patients: 2 weeks

\section{Risk of bias}

Bias Authors' judgement Support for judgement


Kimbrell 1999 (Continued)

$\begin{aligned} & \text { Allocation concealment } \\ & \text { (selection bias) }\end{aligned}$
Unclear risk B - Unclear

Kimbrell 1999b

Methods This is the previous study and is only to analyse separately high and low frequency vs placebo for base-
line comparison.

\section{Participants}

Interventions

\section{Outcomes}

Notes

\section{Risk of bias}

\begin{tabular}{lll}
\hline Bias & Authors' judgement & Support for judgement \\
\hline $\begin{array}{l}\text { Allocation concealment } \\
\text { (selection bias) }\end{array}$ & Unclear risk & D - Not used \\
\hline
\end{tabular}

Klein 1999

\begin{tabular}{|c|c|}
\hline Methods & $\begin{array}{l}\text { Randomised } \\
\text { double-blind } \\
\text { placebo control } \\
\text { Parallel trial. } \\
\text { Computer-generated random number list. } \\
2 \text { week treatment }\end{array}$ \\
\hline Participants & $\begin{array}{l}\text { Included: } \\
\text { Inpatients } \\
\text { none treatment-resistant } \\
\text { Hight-handed } \\
\text { DSM-IV criteria for major depression. } \\
\text { Clinical interview and review of past data. } \\
\text { >15 in (HDRS) } \\
\text { Excluded: } \\
\text { history of major brain trauma, seizure disorder, substance abuse. } \\
\text { Number randomised: } 70 \\
\text { Mean age: } 58.2 \text { (17.2) } \\
\text { Men: } 17 \\
\text { Women: } 53 \\
3 \text { withdrawals } \\
\text { Patients were maintained with their previous medication regimens }\end{array}$ \\
\hline Interventions & $\begin{array}{l}\text { rTMS ( } 1 \mathrm{~Hz} \text { at } 110 \% \text { motor threshold, } 1200 \text { total pulses, } 2 \text { trains per session, } 60 " \text { train duration) over the } \\
\text { right prefrontal cortex + current medication vs Sham TMS + current medication Coil: circular } 9 \mathrm{~cm} \text {. }\end{array}$ \\
\hline Outcomes & $\begin{array}{l}\text { Hamilton Depression Rating Scale-17 item } \\
\text { Montgomery-Asberg Depression Rating Scale }\end{array}$ \\
\hline
\end{tabular}


Klein 1999 (Continued)

Global Impression Scale

Notes The patients were assessed by a single rater (senior psychiatry, who was involved in the diagnostic evaluation but was blind to the nature of treatment.

\section{Risk of bias}

\begin{tabular}{lll}
\hline Bias & Authors' judgement & Support for judgement \\
\hline $\begin{array}{l}\text { Allocation concealment } \\
\text { (selection bias) }\end{array}$ & Unclear risk & B - Unclear \\
\hline
\end{tabular}

\section{Kolbinger 1995}

\begin{tabular}{ll}
\hline Methods & $\begin{array}{l}\text { Randomised } \\
\text { semi-blinded } \\
\text { Parallel trial. }\end{array}$ \\
\hline Participants & Included: \\
& Inpatients \\
& Major depression according to DSM-III-R criteria. \\
& In the 21-item Hamilton Depression Scale, the mean initial score was 21. \\
& No subject had a non affective psychiatric disorder (acute manic symptoms or relevant suicide risk). \\
& Excluded: \\
& History of epilepsy, brain surgery, mobile metal implants, pacemaker, implanted pump system, neuro- \\
& logical or any other serious medical illness. \\
& Men: 5 \\
& Women: 10 \\
& mean age 49 (range 31-68). \\
& Twelve patients were treated with antidepressive medication during the study. In these patients there \\
& was no change in medication at least two weeks before or during the study.
\end{tabular}

Interventions

rTMS ( $\mathrm{mt}+0.3$ tesla, 0.25 to $0.5 \mathrm{~Hz}$ ) over Vertex +- current antidepressive medication vs rTMS ( $\mathrm{mt}-0.3$ tesla, 0.25 to $0.5 \mathrm{~Hz}$ ) over Vertex +- current antidepressive medication vs Sham TMS $(<0.05$ tesla) +- current antidepressive medication

Coil: circular

\begin{tabular}{ll}
\hline Outcomes & Hamilton Depression Scale-21 item \\
& Clinical global Impression \\
& Adjective mood Scale of von Zerssen (Bf-S/Bf-S')
\end{tabular}

Notes We have not used the placebo group because this group was adding to the trial without
randomisation.

\section{Risk of bias}

\begin{tabular}{lll}
\hline Bias & Authors' judgement & Support for judgement \\
\hline $\begin{array}{l}\text { Allocation concealment } \\
\text { (selection bias) }\end{array}$ & Unclear risk & B - Unclear \\
\hline
\end{tabular}

Loo 1999

Methods Randomised double-blind


Loo 1999 (Continued)

placebo control

Parallel trial

4 week treatment

Included:
Pedication resistant
DSM-IV criteria for major depressive episode.
>25 on Montgomery-Asberg Depression Rating Scale.
Excluded:
Major physical or neurological abnormalities, patients treated with ECT during the current episode.
Number randomised: 18
Mean age: 45.7 (14.7) real
Mean age: 50.9 (14.7) sham
Men: 9
Women: 9
0 withdrawal
Patients: (8 Had melancholic features, 3 had a hastory of bipolar disorder, 1 had psychotic features)
Antidepressants were withdrawn 5 days before rTMS for 5 patients. For antidepressants that had failed
to show an effects, steady doses were maintained for 2 weeks before and throughout the estudy (ven-
lafaxine administered to 9 patients and nefazadone to 4 patients)

Interventions

rTMS $(10 \mathrm{~Hz}$ at $110 \%$ motor threshold, 15000 total pulses, 30 trains per session, 5 " train duration) over the left dorsolateral prefrontal cortex +- current medication vs Sham TMS +- current medication Coil: fig. 8

\begin{tabular}{ll}
\hline Outcomes & Hamilton Depression Rating Scale \\
& Beck Depression Inventory \\
& Montgomery-Asberg Depression Rating Scale \\
CORE Scale & AUSSI Scale \\
Neuropsychological tasks & \\
\hline Notes & 2 week treatment (RCT) + 2 week open trial with all the patients (Second phase excluded from the re- \\
& view)
\end{tabular}

\section{Risk of bias}

\section{Bias}

Allocation concealment

(selection bias)

\section{Authors' judgement Support for judgement}

Unclear risk B - Unclear

\section{Mosimann In Press}

\begin{tabular}{ll}
\hline Methods & $\begin{array}{l}\text { Randomised } \\
\text { double-blind } \\
\text { placebo control } \\
\text { Parallel trial } \\
2 \text { weeks treatment }\end{array}$ \\
\hline Participants & Included: \\
& Medication-resistant \\
& Outpatients in the age range of 40 to 80 years. \\
& DSM-IV criteria for major depression. \\
& Excluded: \\
& current or past history of head injury, epilepsy, comorbid unstable medical or neurological illness and \\
& women with adequate methods of birth control.
\end{tabular}


Mosimann In Press (Continued)

Antidepressant medication was not an exclusion criterion. Dosage had to be stable for at least two weeks and no new psychoactive drug could have been started for at least six weeks before the first stimulation.

Number randomized: 24

Mean age: 60.87 (13.25)

Sham group: $64.44(13.03)$

rTMS group: $58.73(13.03)$

0 withdrawal

Sixteen patients were treated with a combination of different antidepressants and 10 patients were treated with mood stabilizers.

Interventions

rTMS $(20 \mathrm{~Hz}$ at $100 \%$ motor threshold, 16000 total pulses, 40 trains per session, 2 " train duration) over the left dorsolateral prefrontal cortex + current medication vs sham TMS + current medication.

Coil: fig. 8

\begin{tabular}{ll}
\hline Outcomes & Hamilton Depression Rating Scale \\
& Beck Depression Inventory \\
& NIMH-Self Rated Symptom Scale (items 1, 6, 15, 18) \\
Visual Analogue Scale assesing depressive symptoms. \\
Neuropsychological tests.
\end{tabular}

Notes

Outcome ratings were performed outside of the research laboratiry by a blinded rater, who was not part of the research group and had no contact to the physicians who applied rTMS. Side effects were assessed by open questions after the stimulation.

\section{Risk of bias}

\begin{tabular}{lll}
\hline Bias & Authors' judgement & Support for judgement \\
\hline $\begin{array}{l}\text { Allocation concealment } \\
\text { (selection bias) }\end{array}$ & Unclear risk & B - Unclear \\
\hline
\end{tabular}

\section{Padberg 1999b}

Methods This is the previous study and is only to analyse separately high and low frequency vs placebo for base-
line comparison.

\section{Participants}

Interventions

\section{Outcomes}

Notes

\section{Risk of bias}

\begin{tabular}{lll}
\hline Bias & Authors' judgement & Support for judgement \\
\hline $\begin{array}{l}\text { Allocation concealment } \\
\text { (selection bias) }\end{array}$ & Unclear risk & D - Not used \\
\hline
\end{tabular}


Pridmore 2000 b

\begin{tabular}{|c|c|c|}
\hline Methods & \multicolumn{2}{|l|}{$\begin{array}{l}\text { Randomized } \\
\text { single-blind } \\
\text { parallel trial }\end{array}$} \\
\hline Participants & \multicolumn{2}{|c|}{$\begin{array}{l}\text { Included: } \\
\text { Medication-resistant } \\
\text { Inpatients and outpatients. } \\
\text { Right-handed } \\
\text { DSM-IV criteria for major depressive disorder. } \\
\text { Excluded: } \\
\text { Free of epilepsy and intracranial metal objects. } \\
\text { Number randomized:22 } \\
\text { Mean age: } 44.40 \text { (12.82) } \\
\text { ECT: } 44.81(15.44) \\
\text { ECT+rTMS: } 44(11.09) \\
\text { Patients who were taking antidepressants or mood stabilizers were continued on those medications. } \\
\text { All other psychotropics was ceased one week before treatment was commenced. }\end{array}$} \\
\hline Interventions & \multicolumn{2}{|c|}{$\begin{array}{l}\text { rTMS ( } 20 \mathrm{~Hz} \text { at } 100 \% \text { motor threshold, } 30 \text { trains per session, } 2 \text { " train duration) over the left prefrontal } \\
\text { cortex + UL ECT + current medication vs UL ECT + current medication. } \\
\text { Coil: fig. } 8\end{array}$} \\
\hline Outcomes & \multicolumn{2}{|c|}{$\begin{array}{l}\text { Hamilton Depression Rating Scale } \\
\text { Montgomery-Asberg Depression Rating Scale } \\
\text { Global Assessment of Functioning Scale } \\
\text { A six-item subjetive side-effects questionnaire. }\end{array}$} \\
\hline Notes & \multicolumn{2}{|c|}{$\begin{array}{l}\text { We have not used this study for quantitative analysis because we can not differentiate the placebo ef- } \\
\text { fect of rTMS treatment }\end{array}$} \\
\hline \multicolumn{3}{|l|}{ Risk of bias } \\
\hline Bias & Authors' judgement & Support for judgement \\
\hline $\begin{array}{l}\text { Allocation concealment } \\
\text { (selection bias) }\end{array}$ & Unclear risk & B - Unclear \\
\hline
\end{tabular}

Characteristics of excluded studies [ordered by study ID]

\begin{tabular}{ll}
\hline Study & Reason for exclusion \\
\hline Bohning 1999 & Healthy adults \\
\hline Clark 2000 & Healthy volunteers \\
\hline Conca 2000 & No control group \\
\hline d'Alfonso 2000 & Selective attention in healthy female subjects \\
\hline Epstein 1998 & No control group \\
\hline Feinsod 1998 & No control group for depression \\
\hline Figiel 1998 & No control group \\
\hline
\end{tabular}




\begin{tabular}{|c|c|}
\hline Study & Reason for exclusion \\
\hline García 1998 & Case series \\
\hline Geller 1997 & No control group \\
\hline George 1999 & Review \\
\hline George 1995 b & No control group \\
\hline George 1996 & Healthy volunteers \\
\hline George 1998 & Case report \\
\hline George 1999 & Review \\
\hline Grisaru 1998 & Controlled study in mania \\
\hline Habel 2001 & Healthy subjects. \\
\hline Hansen 2000 & Review \\
\hline Höflich 1993 & Case series \\
\hline Koppi 1997 DELETE & Trial reported in Conca-96 \\
\hline Kozel 2000 DELETE & Clinical outcomes in George- 00 \\
\hline Krystal 2000 & Review \\
\hline Loo 2000 & Healthy adults \\
\hline Loo 2001 DELETE & Efficacy results from this study have been previously reported \\
\hline Markwort 1997 & Review \\
\hline McConnell 2001 & Healthy adults \\
\hline Menkes 1999 & Case-control study \\
\hline Mosimann 2000 & Healthy male subjects \\
\hline Nahas 1999 & Case report \\
\hline Nahas 2000 & The results from this study are not included in the objetives of this review \\
\hline Pascual-Leone 1996b & Normal volunteers \\
\hline Pridmore 1999a & No control group \\
\hline Pridmore 1999b & No control group \\
\hline Pridmore $1999 \mathrm{c}$ & Review \\
\hline Pridmore 2000 a & Inadequate allocation of treatment (category C) \\
\hline Reid 1999 & Case report \\
\hline
\end{tabular}




\begin{tabular}{ll}
\hline Study & Reason for exclusion \\
\hline Schouten 1999 & No control group \\
\hline Speer 1999 & Outcomes in Kimbrell-99 \\
\hline Stikhina 1999 & No random allocation \\
\hline Szuba 2000 & Review \\
\hline Teneback 1999 & Clinical outcomes in George-00 \\
\hline Tormos 1999 & Review \\
\hline Triggs 1999 & No control group \\
\hline Turnier-Shea 1999 & Descriptive Study \\
\hline Walter 2001 & Review in young psychiatric patients \\
\hline Zheng 2000 & No control group \\
\hline
\end{tabular}

Characteristics of ongoing studies [ordered by study ID]

Adsersen-1

Trial name or title

\section{Methods}

\begin{tabular}{ll}
\hline Participants & Patients with major depressive disorder \\
\hline Interventions & 10 sessions. \\
& rTMS: $10 \mathrm{~Hz}$ at $100 \%$ motor threshold, 16000 total pulses, 20 trains per session, $5 "$ \\
& train duration. \\
& Coil: fig. 8 \\
\hline
\end{tabular}

Outcomes

\section{Starting date}

Contact information

\section{Notes}

Avery-1

Trial name or title

\section{Methods}

\section{Participants}

Interventions
Patients with major depressive disorder

10 sessions.

Transcranial magnetic stimulation for treating depression (Review) 
Avery-1 (Continued)

rTMS: $10 \mathrm{~Hz}$ at $90-100 \%$ motor threshold, 16000 total pulses, 32 trains per session, 5 " train duration over the left dorsolateral prefrontal cortex

Coil: fig.8

\section{Outcomes}

\section{Starting date}

Contact information

\section{Notes}

\section{D'Alfonso-1}

Trial name or title

\section{Methods}

Participants

Patients with major depressive disorder

Interventions

10 sessions

rTMS: $10 \mathrm{~Hz}$ at $90-100 \%$ motor threshold, 10000 total pulses, 20 trains per session, 5"

train duration over the left dorsolateral prefrontal cortex

\section{Outcomes}

\section{Starting date}

\section{Contact information}

\section{Notes}

Ebmeier-1

\section{Trial name or title}

\section{Methods}

\begin{tabular}{ll}
\hline Participants & Patients with major depressive disorder \\
\hline Interventions & 10 sessions \\
& rTMS: 5,10 and $20 \mathrm{~Hz}$ at $100 \%$ motor threshold, 5000 total pulses, 25 trains per session, 4 ", 2 " and \\
& $\begin{array}{l}\text { " train duration over the the left dorsolateral prefrontal cortex. } 5 \text { patients in each group without } \\
\text { placebo group. } \\
\text { Coil: fig. } 8\end{array}$ \\
\hline
\end{tabular}

\section{Outcomes}

\section{Starting date}

\section{Contact information}

\section{Notes}


Eckert-1

\section{Trial name or title}

\section{Methods}

\begin{tabular}{ll}
\hline Participants & Patients with bipolar mood disorder \\
\hline Interventions & $6-20$ sessions. \\
& rTMS: $10 \mathrm{~Hz}$ at $100 \%$ motor threshold, $4200-14000$ total pulses, 20 trains per session, \\
& $3.5^{\prime \prime}$ train duration \\
Coil: fig. circular $13 \mathrm{~cm}$
\end{tabular}

\section{Outcomes}

\section{Starting date}

\section{Contact information}

\section{Notes}

Greenberg-1

\section{Trial name or title}

\section{Methods}

\begin{tabular}{ll}
\hline Participants & Patients with major depressive disorder \\
\hline Interventions & 4 sessions Localisation: 4 sites. rTMS: $20 \mathrm{~Hz}$ at $80 \%$ motor threshold, 48000 total pulses, \\
& 40 trains per session, 2 " train duration. \\
& Coil: fig. 8 \\
\hline
\end{tabular}

\section{Outcomes}

\section{Starting date}

Contact information

\section{Notes}

\section{McLoughlin-1}

\begin{tabular}{ll}
\hline Trial name or title & $\begin{array}{l}\text { Clinical effectiveness and cost of repetitive transcranial magnetic stimulation versus ECT in severe } \\
\text { depression: a multi-centre randomised controlled trial and economic analysis }\end{array}$ \\
\hline Methods & Patients with severe depression \\
\hline Participants & $\begin{array}{l}\text { rTMS vs ECT. } \\
\text { Ninety patients will be entered into each arm of the trial. }\end{array}$ \\
\hline
\end{tabular}


McLoughlin-1 (Continued)

Outcomes

Objetives: to determine if rTMS is as effective as ECT; to determine if rTMS is associated with fewer side effects than ECT; to identify patient characteristics indicative of beneficial response to rTMS; to ascertain patient preference for rTMS or ECT; to carry out a cost-effectiveness analysis of the use of rTMS versus ECT.

\begin{tabular}{ll}
\hline Starting date & August 2001 \\
\hline Contact information & \\
\hline Notes & \\
\hline
\end{tabular}

\section{Paradiso-1}

Trial name or title

\section{Methods}

\begin{tabular}{ll}
\hline Participants & Patients with major depressive disorder \\
\hline Interventions & 5 sessions \\
& rTMS: 10 or $20 \mathrm{~Hz}$ at $80 \%$ motor threshold. 4000 or 5000 total pulses, 20 trains per session, $2^{\prime \prime}$ \\
& or 5" train duration over the left dorsolateral prefrontal cortex. \\
Coil: fig. 8
\end{tabular}

\section{Outcomes}

\section{Starting date}

Contact information

\section{Notes}

\section{Pascual-Leone-1}

\section{Trial name or title}

\section{Methods}

Participants Patients with major depressive disorder

\begin{tabular}{ll}
\hline Interventions & 10 sessions. \\
& rTMS: $10 \mathrm{~Hz}$ at $90-110 \%$ motor treshold, 16000 total pulses, 20 trains per session, 8 " train \\
& duration over the left or right dorsolateral prefrontal cortex \\
& Coil: fig.8
\end{tabular}

\section{Outcomes}

\section{Starting date}

\section{Contact information}

\section{Notes}


Pascual-Leone-2

\section{Trial name or title}

\section{Methods}

\section{Participants}

Interventions

10 sessions

rTMS: $20 \mathrm{~Hz}$ at $90 \%$ motor threshold, 12000 total pulses, 30 trains per session, 2" train duration over the left dorsolateral prefrontal cortex.

Coil: fig.8

\section{Outcomes}

\section{Starting date}

\section{Contact information}

\section{Notes}

Sackeim-1

\section{Trial name or title}

\section{Methods}

\section{Participants}

Interventions

\section{Outcomes}

Starting date

\section{Contact information}

Notes

\section{Schaepfer-1}

\section{Trial name or title}

\section{Methods}

\section{Participants}

Interventions

10 sessions.

rTMS: $20 \mathrm{~Hz}$ at $80 \%$ motor threshold, 16000 total pulses, 40 trains per session, 2" train duration over the left dorsolateral prefrontal cortex.

Coil: fig.8 
Schaepfer-1 (Continued)

Outcomes

Starting date

Contact information

\section{Notes}

\section{Shajahan-1}

Trial name or title

The treatment of partial remission in depression using transcranial magnetic stimulation (TMS): Open pilot trial followed by randomised placebo controlled cross-over study

\section{Methods}

\section{Participants}

Patients with DSM IV defined major depressive episode not responding optimally to medication

\section{Interventions}

\section{Outcomes}

Hamilton depressin rating scores (blindly), Beck depression score, neuropsychological profiling

Starting date $01 / 04 / 2000$

Contact information

\section{Notes}

\section{Szuba-1}

Trial name or title

\section{Methods}

\begin{tabular}{ll}
\hline Participants & Patients with major depressive disorder \\
\hline Interventions & $\begin{array}{l}\text { rTMS: } 10 \mathrm{~Hz} \text { at } 100 \% \text { motor threshold, } 20 \text { trains per session, } 5 \text { " train duration over } \\
\text { the left dorsolateral prefrontal cortex } \\
\text { Coil: fig.8 }\end{array}$
\end{tabular}

\section{Outcomes}

\section{Starting date}

\section{Contact information}

\section{Notes}

Weber-1

\section{Trial name or title}


Weber-1 (Continued)

Methods

\begin{tabular}{ll}
\hline Participants & Patients with bipolar mood disorder \\
\hline Interventions & $\begin{array}{l}\text { 1 session } \\
\text { rTMS: } 10 \mathrm{~Hz} .700 \text { total pulses, } 20 \text { trains per session, 3.5" train duration over the left } \\
\text { prefrontal cortex } \\
\text { Coil: circular } 13 \mathrm{~cm} .\end{array}$ \\
\hline Outcomes & \\
\hline Starting date & \\
\hline Contact information & \\
\hline Notes & \\
\hline
\end{tabular}

Woodruff-1

Trial name or title Cost effectiveness of transcranial magnetic stimulation and electro-convulsive treatment in severe depression (TRANSECT)

\section{Methods}

\begin{tabular}{ll}
\hline Participants & Patients referred to psychiatry services in outpatient clinics and inpatients \\
\hline Interventions & $\begin{array}{l}40 \% \text { reduction in HAMD @ } 6 \text { weeks and } 10 \% \text { improvement in SF36 score. Time to remission } \\
\text { (HAMD }<10), \text { time to relapse (HAMD rating }>15 \text { plus increase by } 4 \text { points) or change in clinical man- } \\
\text { agement due to recurrence, direct and indirect cost }\end{array}$ \\
\hline Outcomes & $01 / 03 / 2000$ \\
\hline Contact information & \\
\hline Notes & \\
\hline
\end{tabular}

\section{DATA AND ANALYSES}

\section{Comparison 1. rTMS (left and high) vs Sham TMS}

\begin{tabular}{lllll}
\hline Outcome or subgroup title & No. of studies & $\begin{array}{l}\text { No. of partici- } \\
\text { pants }\end{array}$ & Statistical method & Effect size \\
\hline $\begin{array}{l}1 \text { Symptoms (Hamilton } \\
\text { Scale) }\end{array}$ & 11 & & Std. Mean Difference (IV, Fixed, 95\% Cl) & Subtotals only \\
\hline \begin{tabular}{llll}
1.1 One week \\
\hline
\end{tabular} & 3 & 34 & Std. Mean Difference (IV, Fixed, 95\% Cl) & $0.02[-0.66,0.70]$ \\
\hline
\end{tabular}




\begin{tabular}{|c|c|c|c|c|}
\hline Outcome or subgroup title & No. of studies & $\begin{array}{l}\text { No. of partici- } \\
\text { pants }\end{array}$ & Statistical method & Effect size \\
\hline $\begin{array}{l}\text { 1.2 One week follow-up (af- } \\
\text { ter one week of treatment) }\end{array}$ & 1 & 10 & Std. Mean Difference (IV, Fixed, 95\% CI) & $0.55[-0.73,1.82]$ \\
\hline 1.3 Two weeks & 9 & 175 & Std. Mean Difference (IV, Fixed, 95\% CI) & $-0.35[-0.66,-0.04]$ \\
\hline $\begin{array}{l}\text { 1.4 Two weeks follow-up } \\
\text { (after two weeks of treat- } \\
\text { ment) }\end{array}$ & 3 & 63 & Std. Mean Difference (IV, Fixed, 95\% CI) & $-0.33[-0.84,0.17]$ \\
\hline 2 Symptoms (Beck Scale) & 7 & & Std. Mean Difference (IV, Fixed, 95\% CI) & Subtotals only \\
\hline 2.1 One Week & 3 & 38 & Std. Mean Difference (IV, Fixed, 95\% CI) & $0.18[-0.47,0.82]$ \\
\hline $\begin{array}{l}2.2 \text { One week follow-up (af- } \\
\text { ter one week of treatment) }\end{array}$ & 1 & 10 & Std. Mean Difference (IV, Fixed, 95\% CI) & $0.52[-0.75,1.80]$ \\
\hline 2.3 Two Weeks & 6 & 135 & Std. Mean Difference (IV, Fixed, 95\% CI) & $-0.24[-0.58,0.11]$ \\
\hline $\begin{array}{l}\text { 2.4 Two weeks follow-up } \\
\text { (after two weeks of treat- } \\
\text { ment) }\end{array}$ & 3 & 63 & Std. Mean Difference (IV, Fixed, 95\% CI) & $-0.06[-0.56,0.43]$ \\
\hline $\begin{array}{l}3 \text { Clinical Global Improve- } \\
\text { ment }\end{array}$ & 1 & & Mean Difference (IV, Fixed, 95\% CI) & Subtotals only \\
\hline 3.1 Two weeks & 1 & 30 & Mean Difference (IV, Fixed, 95\% CI) & $-0.70[-1.77,0.37]$ \\
\hline
\end{tabular}

Analysis 1.1. Comparison 1 rTMS (left and high) vs Sham TMS, Outcome 1 Symptoms (Hamilton Scale).

\begin{tabular}{|c|c|c|c|c|c|c|c|}
\hline \multirow{3}{*}{$\begin{array}{l}\text { Study or subgroup } \\
1.1 .1 \text { One week }\end{array}$} & \multicolumn{2}{|c|}{ Treatment } & \multicolumn{2}{|c|}{ Control } & \multirow{2}{*}{$\begin{array}{c}\text { Std. Mean Difference } \\
\text { Fixed, } 95 \% \mathrm{Cl}\end{array}$} & \multirow[t]{2}{*}{ Weight } & \multirow{2}{*}{$\begin{array}{l}\text { Std. Mean Difference } \\
\text { Fixed, } 95 \% \mathrm{Cl}\end{array}$} \\
\hline & $\mathbf{N}$ & $\operatorname{Mean}(S D)$ & $\mathbf{N}$ & Mean(SD) & & & \\
\hline & & & & & & & \\
\hline Eschweiler 2000 & 5 & $23.2(4.6)$ & 5 & $23.2(5.8)$ & $\hookrightarrow$ & $30.45 \%$ & $0[-1.24,1.24]$ \\
\hline George 1997 & 7 & $25(4)$ & 5 & $27(5)$ & $\rightarrow$ & $34.44 \%$ & $-0.42[-1.58,0.75]$ \\
\hline Haag 1997 & 6 & $28.5(9.4)$ & 6 & $23.5(10.4)$ & & $35.12 \%$ & $0.47[-0.69,1.62]$ \\
\hline Subtotal ${ }^{\star \star \star}$ & 18 & & 16 & & & $100 \%$ & $0.02[-0.66,0.7]$ \\
\hline \multicolumn{8}{|c|}{ Heterogeneity: $\operatorname{Tau}^{2}=0 ; \mathrm{Chi}^{2}=1.11, \mathrm{df}=2(\mathrm{P}=0.57) ; \mathrm{I}^{2}=0 \%$} \\
\hline \multicolumn{8}{|c|}{ Test for overall effect: $Z=0.06(P=0.95)$} \\
\hline \multicolumn{8}{|c|}{ 1.1.2 One week follow-up (after one week of treatment) } \\
\hline Eschweiler 2000 & 5 & $22.6(5.1)$ & 5 & $18.8(7.3)$ & & $100 \%$ & $0.55[-0.73,1.82]$ \\
\hline 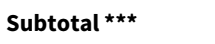 & 5 & & 5 & & & $100 \%$ & $0.55[-0.73,1.82]$ \\
\hline \multicolumn{8}{|c|}{ Heterogeneity: Not applicable } \\
\hline \multicolumn{8}{|l|}{ 1.1.3 Two weeks } \\
\hline Avery 1999 & 4 & $10.8(3.5)$ & 2 & $15(2.5)$ & 1 & $2.5 \%$ & $-1.02[-2.99,0.94]$ \\
\hline Berman $2000 \mathrm{~b}$ & 10 & $24.6(8.8)$ & 10 & $36.4(8.6)$ & $\rightarrow$ & $9.95 \%$ & $-1.3[-2.29,-0.32]$ \\
\hline García-Toro 2001 a & 17 & $20.1(7.9)$ & 18 & $23.8(6.2)$ & *- & $21.18 \%$ & $-0.52[-1.2,0.15]$ \\
\hline \multirow[t]{2}{*}{ García-Toro 2001 c } & 11 & $16.1(7.7)$ & 11 & $17.9(8.7)$ & $\rightarrow$ & $13.74 \%$ & $-0.21[-1.05,0.63]$ \\
\hline & & & Fav & ment $\quad-10$ & -5 & Favours & \\
\hline
\end{tabular}




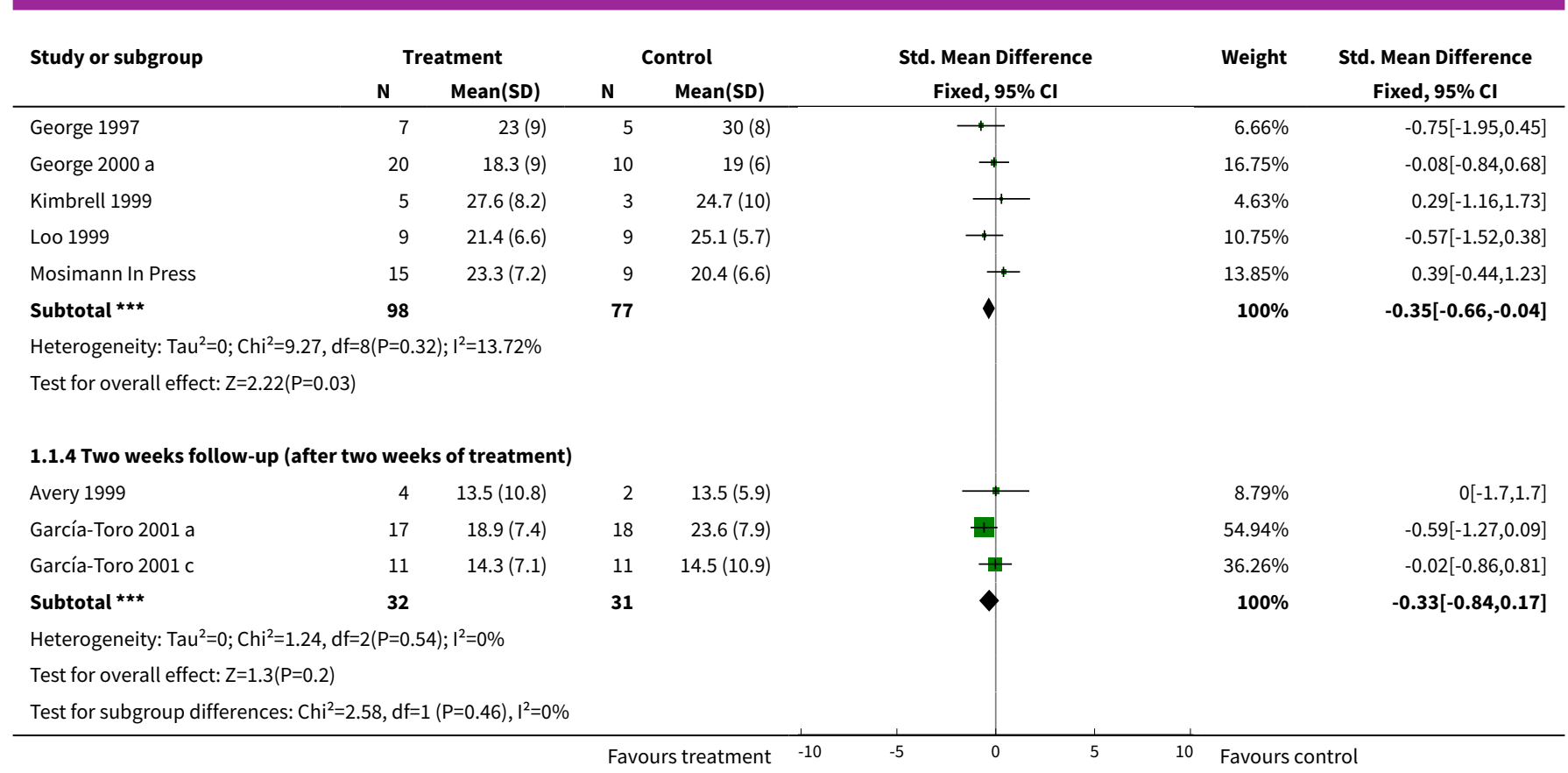

Analysis 1.2. Comparison 1 rTMS (left and high) vs Sham TMS, Outcome 2 Symptoms (Beck Scale).

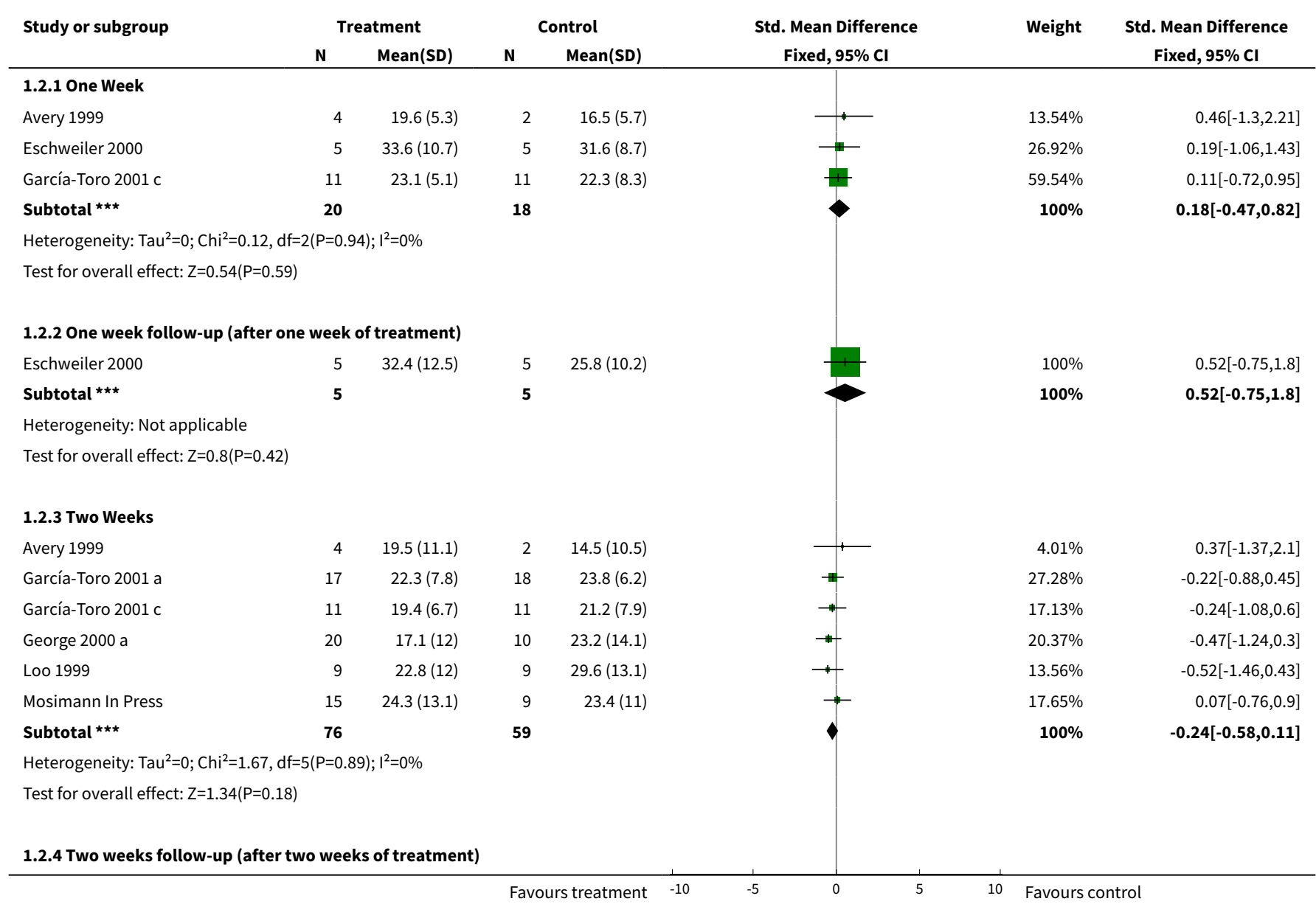




\begin{tabular}{|c|c|c|c|c|c|c|c|}
\hline \multirow[t]{2}{*}{ Study or subgroup } & \multicolumn{2}{|c|}{ Treatment } & \multicolumn{2}{|c|}{ Control } & \multirow{2}{*}{$\begin{array}{c}\text { Std. Mean Difference } \\
\text { Fixed, } 95 \% \mathrm{Cl}\end{array}$} & \multirow[t]{2}{*}{ Weight } & \multirow{2}{*}{$\begin{array}{l}\text { Std. Mean Difference } \\
\text { Fixed, } 95 \% \mathrm{Cl}\end{array}$} \\
\hline & $\mathbf{N}$ & Mean(SD) & $\mathbf{N}$ & Mean(SD) & & & \\
\hline Avery 1999 & 4 & $20.3(16.1)$ & 2 & $16.5(11.4)$ & 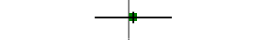 & $8.49 \%$ & $0.2[-1.51,1.91]$ \\
\hline García-Toro 2001 a & 17 & $22.9(9.4)$ & 18 & $24.7(7.2)$ & $\pi$ & $56.07 \%$ & $-0.21[-0.87,0.46]$ \\
\hline García-Toro 2001 c & 11 & $19.5(7.4)$ & 11 & $18.5(11.1)$ & 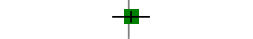 & $35.43 \%$ & $0.1[-0.73,0.94]$ \\
\hline 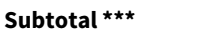 & 32 & & 31 & & & $100 \%$ & $-0.06[-0.56,0.43]$ \\
\hline \multicolumn{8}{|c|}{ Heterogeneity: $\mathrm{Tau}^{2}=0 ; \mathrm{Chi}^{2}=0.43, \mathrm{df}=2(\mathrm{P}=0.81) ; \mathrm{I}^{2}=0 \%$} \\
\hline \multicolumn{8}{|c|}{ Test for overall effect: $Z=0.25(P=0.8)$} \\
\hline \multicolumn{8}{|c|}{ Test for subgroup differences: $\mathrm{Chi}^{2}=2.25, \mathrm{df}=1(\mathrm{P}=0.52), \mathrm{I}^{2}=0 \%$} \\
\hline
\end{tabular}

Analysis 1.3. Comparison 1 rTMS (left and high) vs Sham TMS, Outcome 3 Clinical Global Improvement.

\begin{tabular}{|c|c|c|c|c|c|c|c|}
\hline \multirow[t]{2}{*}{ Study or subgroup } & \multicolumn{2}{|c|}{ Treatment } & \multicolumn{2}{|c|}{ Control } & \multirow{2}{*}{$\begin{array}{c}\text { Mean Difference } \\
\text { Fixed, } 95 \% \mathrm{Cl}\end{array}$} & \multirow[t]{2}{*}{ Weight } & \multirow{2}{*}{$\begin{array}{c}\text { Mean Difference } \\
\text { Fixed, } 95 \% \mathrm{Cl}\end{array}$} \\
\hline & $\mathbf{N}$ & Mean(SD) & $\mathbf{N}$ & Mean(SD) & & & \\
\hline \multicolumn{8}{|l|}{ 1.3.1 Two weeks } \\
\hline George 2000 a & 20 & $3.1(1.2)$ & 10 & $3.8(1.5)$ & & $100 \%$ & $-0.7[-1.77,0.37]$ \\
\hline 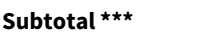 & 20 & & 10 & & & $100 \%$ & $-0.7[-1.77,0.37]$ \\
\hline \multicolumn{8}{|c|}{ Heterogeneity: $\mathrm{Tau}^{2}=0 ; \mathrm{Chi}^{2}=0, \mathrm{df}=0(\mathrm{P}<0.0001) ; \mathrm{I}^{2}=100 \%$} \\
\hline \multicolumn{8}{|c|}{ Test for overall effect: $Z=1.28(P=0.2)$} \\
\hline
\end{tabular}

\section{Comparison 2. rTMS (left and low) vs Sham TMS}

\begin{tabular}{lllll}
\hline $\begin{array}{l}\text { Outcome or subgroup } \\
\text { title }\end{array}$ & No. of studies & $\begin{array}{l}\text { No. of partici- } \\
\text { pants }\end{array}$ & Statistical method & Effect size \\
\hline $\begin{array}{l}1 \text { Symptoms (Hamilton } \\
\text { Scale) }\end{array}$ & 2 & & Mean Difference (IV, Fixed, 95\% Cl) & Subtotals only \\
\hline 1.1 One week & 1 & 12 & Mean Difference (IV, Fixed, 95\% Cl) & $-2.0[-13.49,9.49]$ \\
\hline 1.2 Two Weeks & 1 & 8 & Mean Difference (IV, Fixed, 95\% Cl) & $2.53[-13.53,18.59]$ \\
\hline
\end{tabular}

Analysis 2.1. Comparison 2 rTMS (left and low) vs Sham TMS, Outcome 1 Symptoms (Hamilton Scale).

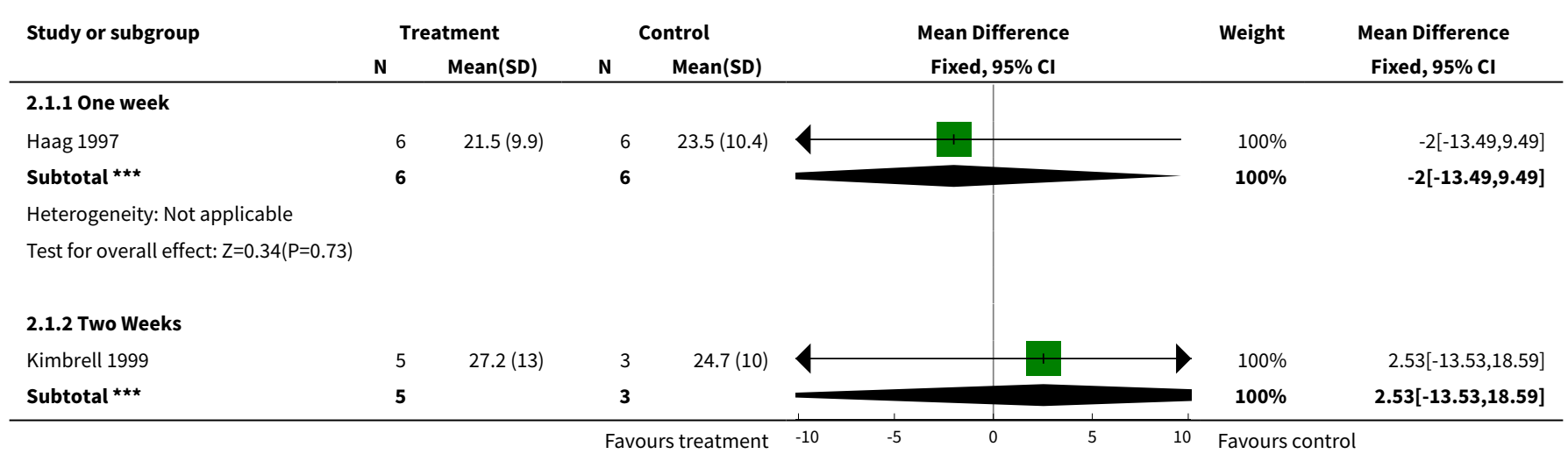




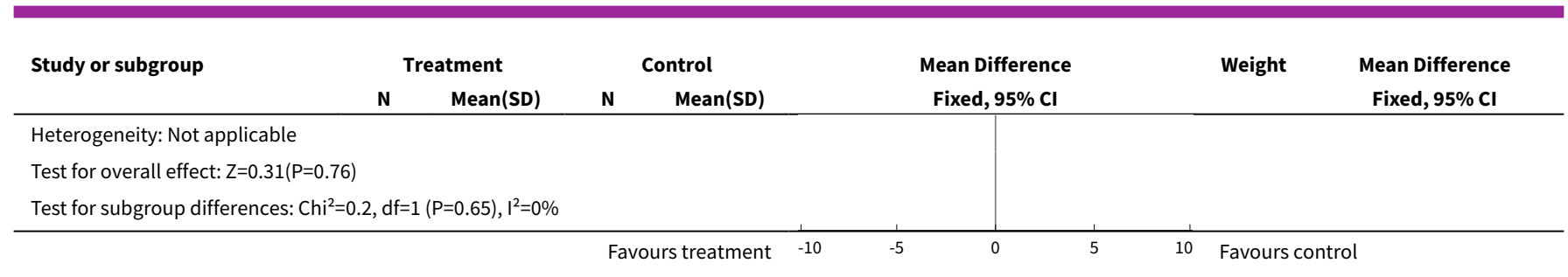

\section{Comparison 3. rTMS (right and low) vs Sham TMS}

\begin{tabular}{lllll}
\hline $\begin{array}{l}\text { Outcome or subgroup } \\
\text { title }\end{array}$ & No. of studies & $\begin{array}{l}\text { No. of partici- } \\
\text { pants }\end{array}$ & Statistical method & Effect size \\
\hline $\begin{array}{l}1 \text { symptoms (Hamilton } \\
\text { Scale) }\end{array}$ & 1 & & Mean Difference (IV, Fixed, 95\% Cl) & Subtotals only \\
\hline $\begin{array}{lllll}1.1 \text { One Week } \\
1.2 \text { Two Weeks }\end{array}$ & 1 & 67 & Mean Difference (IV, Fixed, 95\% Cl) & $-4.20[-8.44,0.04]$ \\
\hline $\begin{array}{l}2 \text { Clinical Global Im- } \\
\text { pression }\end{array}$ & 1 & 67 & Mean Difference (IV, Fixed, 95\% Cl) & $-6.00[-10.69,-1.31]$ \\
\hline 2.1 One week & 1 & Mean Difference (IV, Fixed, 95\% Cl) & Subtotals only \\
\hline 2.2 Two weeks & 1 & 67 & Mean Difference (IV, Fixed, 95\% CI) & $-0.50[-1.11,0.11]$ \\
\hline
\end{tabular}

Analysis 3.1. Comparison 3 rTMS (right and low) vs Sham TMS, Outcome 1 symptoms (Hamilton Scale).

\begin{tabular}{|c|c|c|c|c|c|c|c|}
\hline \multirow[t]{2}{*}{ Study or subgroup } & \multicolumn{2}{|c|}{ Treatment } & \multicolumn{2}{|c|}{ Control } & \multirow{2}{*}{$\begin{array}{c}\text { Mean Difference } \\
\text { Fixed, } 95 \% \mathrm{Cl}\end{array}$} & \multirow[t]{2}{*}{ Weight } & \multirow{2}{*}{$\begin{array}{c}\text { Mean Difference } \\
\text { Fixed, } 95 \% \mathrm{Cl}\end{array}$} \\
\hline & $\mathbf{N}$ & Mean(SD) & $\mathbf{N}$ & Mean(SD) & & & \\
\hline \multicolumn{8}{|l|}{ 3.1.1 One Week } \\
\hline Klein 1999 & 35 & $16.6(7.8)$ & 32 & $20.8(9.7)$ & & $100 \%$ & $-4.2[-8.44,0.04]$ \\
\hline 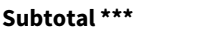 & 35 & & 32 & & & $100 \%$ & $-4.2[-8.44,0.04]$ \\
\hline \multicolumn{8}{|c|}{ Heterogeneity: Not applicable } \\
\hline \multicolumn{8}{|c|}{ Test for overall effect: $Z=1.94(P=0.05)$} \\
\hline \multicolumn{8}{|l|}{ 3.1.2 Two Weeks } \\
\hline Klein 1999 & 35 & $13.7(9.2)$ & 32 & $19.7(10.3)$ & & $100 \%$ & $-6[-10.69,-1.31]$ \\
\hline 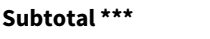 & 35 & & 32 & & & $100 \%$ & $-6[-10.69,-1.31]$ \\
\hline \multicolumn{8}{|c|}{ Heterogeneity: $\operatorname{Tau}^{2}=0 ; \mathrm{Chi}^{2}=0, \mathrm{df}=0(\mathrm{P}<0.0001) ; \mathrm{I}^{2}=100 \%$} \\
\hline \multicolumn{8}{|c|}{ Test for overall effect: $Z=2.51(P=0.01)$} \\
\hline \multicolumn{8}{|c|}{ Test for subgroup differences: $\mathrm{Chi}^{2}=0.31, \mathrm{df}=1(\mathrm{P}=0.58), \mathrm{I}^{2}=0 \%$} \\
\hline
\end{tabular}


Analysis 3.2. Comparison 3 rTMS (right and low) vs Sham TMS, Outcome 2 Clinical Global Impression.

\begin{tabular}{|c|c|c|c|c|c|c|c|}
\hline \multirow[t]{2}{*}{ Study or subgroup } & \multicolumn{2}{|c|}{ Treatment } & \multicolumn{2}{|c|}{ Control } & \multirow{2}{*}{$\begin{array}{c}\text { Mean Difference } \\
\text { Fixed, } 95 \% \mathrm{Cl} \\
\end{array}$} & \multirow[t]{2}{*}{ Weight } & \multirow{2}{*}{$\begin{array}{c}\text { Mean Difference } \\
\text { Fixed, } 95 \% \mathrm{Cl}\end{array}$} \\
\hline & $\mathbf{N}$ & Mean(SD) & $\mathbf{N}$ & $\operatorname{Mean}(S D)$ & & & \\
\hline \multicolumn{8}{|l|}{ 3.2.1 One week } \\
\hline Klein 1999 & 35 & $3.9(1.1)$ & 32 & $4.4(1.4)$ & & $100 \%$ & $-0.5[-1.11,0.11]$ \\
\hline Subtotal ${ }^{\star \star \star}$ & 35 & & 32 & & & $100 \%$ & $-0.5[-1.11,0.11]$ \\
\hline \multicolumn{8}{|c|}{ Heterogeneity: Not applicable } \\
\hline \multicolumn{8}{|c|}{ Test for overall effect: $Z=1.62(P=0.11)$} \\
\hline \multicolumn{8}{|l|}{ 3.2.2 Two weeks } \\
\hline Klein 1999 & 35 & $3.5(1.4)$ & 32 & $4.2(1.5)$ & & $100 \%$ & $-0.7[-1.4,-0]$ \\
\hline Subtotal $* \star \star$ & 35 & & 32 & & & $100 \%$ & $-0.7[-1.4,-0]$ \\
\hline \multicolumn{8}{|c|}{ Heterogeneity: Not applicable } \\
\hline \multicolumn{8}{|c|}{ Test for overall effect: $Z=1.97(P=0.05)$} \\
\hline \multicolumn{8}{|c|}{ Test for subgroup differences: $\mathrm{Chi}^{2}=0.18, \mathrm{df}=1(\mathrm{P}=0.67), \mathrm{I}^{2}=0 \%$} \\
\hline
\end{tabular}

Comparison 4. rTMS (left and high) vs rTMS (left and low)

\begin{tabular}{lllll}
\hline $\begin{array}{l}\text { Outcome or subgroup } \\
\text { title }\end{array}$ & No. of studies & $\begin{array}{l}\text { No. of partici- } \\
\text { pants }\end{array}$ & Statistical method & Effect size \\
\hline $\begin{array}{l}1 \text { Symptoms (Hamilton } \\
\text { Scale) }\end{array}$ & 2 & & Mean Difference (IV, Fixed, 95\% CI) & Subtotals only \\
\hline 1.1 One Week & 1 & 12 & Mean Difference (IV, Fixed, 95\% CI) & $-2.60[-10.76,5.56]$ \\
\hline 1.2 Two Weeks & 1 & 10 & Mean Difference (IV, Fixed, 95\% CI) & $-0.40[-13.84,13.04]$ \\
\hline
\end{tabular}

Analysis 4.1. Comparison 4 rTMS (left and high) vs rTMS (left and low), Outcome 1 Symptoms (Hamilton Scale).

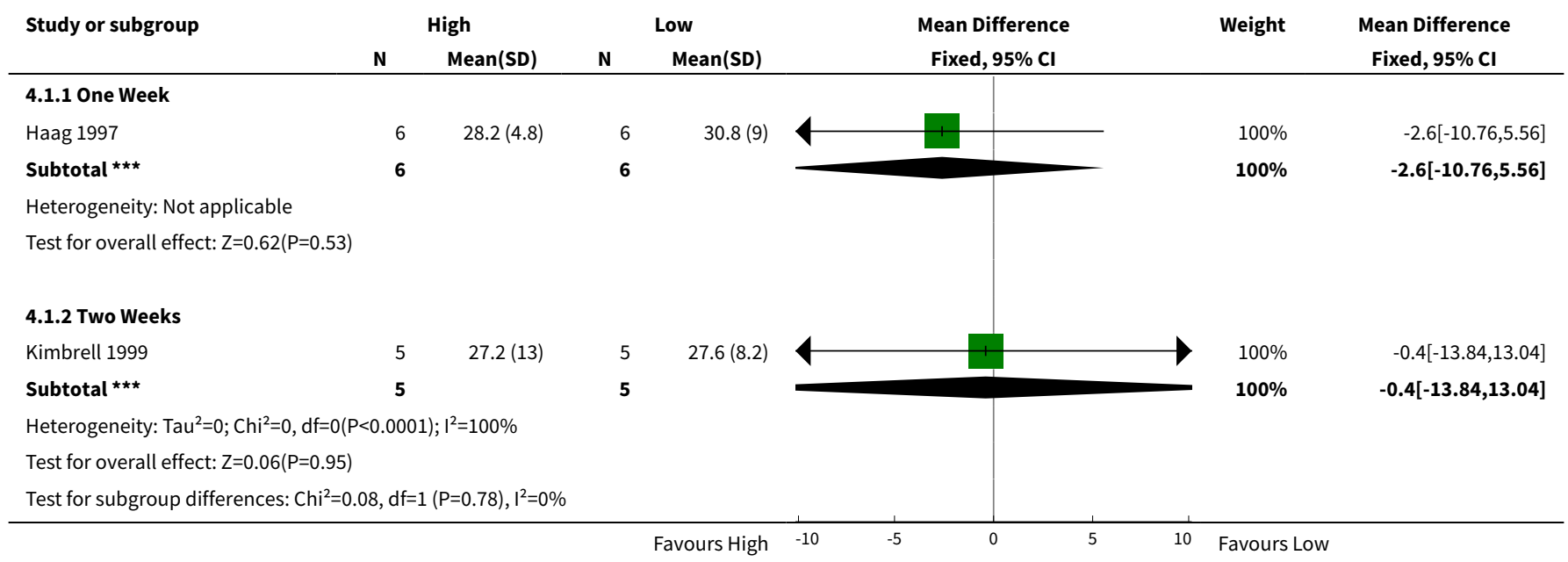


Comparison 5. rTMS (mt + 0.3 Tesla) vs rTMS (mt - 0.3 Tesla)

\begin{tabular}{|c|c|c|c|c|}
\hline $\begin{array}{l}\text { Outcome or subgroup ti- } \\
\text { tle }\end{array}$ & No. of studies & $\begin{array}{l}\text { No. of partici- } \\
\text { pants }\end{array}$ & Statistical method & Effect size \\
\hline $\begin{array}{l}1 \text { Symptoms (Hamilton } \\
\text { Scale) }\end{array}$ & 1 & & Mean Difference (IV, Fixed, 95\% CI) & Subtotals only \\
\hline 1.1 One week & 1 & 10 & Mean Difference (IV, Fixed, 95\% CI) & $6.4[-1.71,14.51]$ \\
\hline $\begin{array}{l}2 \text { Clinical Global Impres- } \\
\text { sion }\end{array}$ & 1 & & Mean Difference (IV, Fixed, 95\% CI) & Subtotals only \\
\hline 2.1 One week & 1 & 10 & Mean Difference (IV, Fixed, 95\% CI) & $0.40[-1.33,2.13]$ \\
\hline
\end{tabular}

Analysis 5.1. Comparison 5 rTMS (mt + 0.3 Tesla) vs rTMS (mt - 0.3 Tesla), Outcome 1 Symptoms (Hamilton Scale).

\begin{tabular}{|c|c|c|c|c|c|c|c|}
\hline \multirow[t]{2}{*}{ Study or subgroup } & \multicolumn{2}{|c|}{+0.3 Tesla } & \multicolumn{2}{|c|}{ - 0.3 Tesla } & \multirow{2}{*}{$\begin{array}{c}\text { Mean Difference } \\
\text { Fixed, } 95 \% \mathrm{Cl}\end{array}$} & \multirow[t]{2}{*}{ Weight } & \multirow{2}{*}{$\begin{array}{c}\text { Mean Difference } \\
\text { Fixed, } 95 \% \mathrm{Cl}\end{array}$} \\
\hline & $\mathbf{N}$ & Mean(SD) & $\mathbf{N}$ & Mean(SD) & & & \\
\hline \multicolumn{8}{|l|}{ 5.1.1 One week } \\
\hline Subtotal $\star \star \star$ & 5 & & 5 & & & $100 \%$ & $6.4[-1.71,14.51]$ \\
\hline \multicolumn{8}{|c|}{ Heterogeneity: Not applicable } \\
\hline \multicolumn{8}{|c|}{ Test for overall effect: $Z=1.55(P=0.12)$} \\
\hline
\end{tabular}

Analysis 5.2. Comparison 5 rTMS (mt + 0.3 Tesla) vs rTMS (mt - 0.3 Tesla), Outcome 2 Clinical Global Impression.

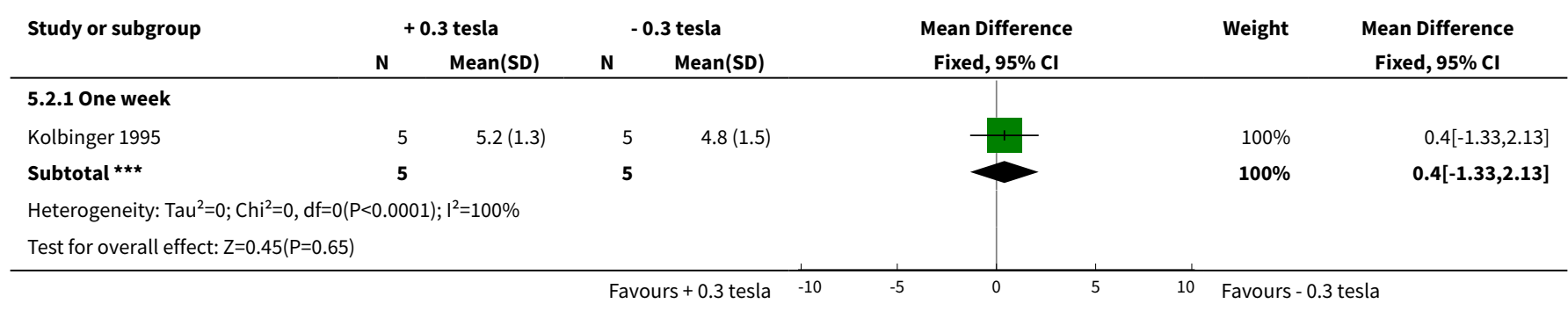

\section{Comparison 6. rTMS (left and high) vs ECT}

\begin{tabular}{lllll}
\hline $\begin{array}{l}\text { Outcome or subgroup ti- } \\
\text { tle }\end{array}$ & No. of studies & $\begin{array}{l}\text { No. of partici- } \\
\text { pants }\end{array}$ & Statistical method & Effect size \\
\hline $\begin{array}{l}1 \text { Symptoms (Hamilton } \\
\text { Scale) all patients }\end{array}$ & 1 & & Mean Difference (IV, Fixed, 95\% Cl) & Subtotals only \\
\hline 1.1 Two Weeks & 1 & 40 & Mean Difference (IV, Fixed, 95\% Cl) & $1.70[-3.27,6.67]$ \\
\hline 1.2 Four weeks & 1 & 40 & Mean Difference (IV, Fixed, 95\% Cl) & $4.20[-0.74,9.14]$ \\
\hline
\end{tabular}




\begin{tabular}{|c|c|c|c|c|}
\hline $\begin{array}{l}\text { Outcome or subgroup ti- } \\
\text { tle }\end{array}$ & No. of studies & $\begin{array}{l}\text { No. of partici- } \\
\text { pants }\end{array}$ & Statistical method & Effect size \\
\hline $\begin{array}{l}2 \text { Symptoms (Hamilton } \\
\text { Scale) Non-psychotic pa- } \\
\text { tients }\end{array}$ & 1 & & Mean Difference (IV, Fixed, 95\% CI) & Subtotals only \\
\hline 2.1 Two Weeks & 1 & 21 & Mean Difference (IV, Fixed, 95\% CI) & $-3.90[-10.90,3.10]$ \\
\hline 2.2 Four Weeks & 1 & 21 & Mean Difference (IV, Fixed, 95\% CI) & $-2.90[-10.26,4.46]$ \\
\hline $\begin{array}{l}3 \text { Symptoms (Hamilton } \\
\text { Scale) psychotic patients }\end{array}$ & 1 & & Mean Difference (IV, Fixed, 95\% CI) & Subtotals only \\
\hline 3.1 Two Weeks & 1 & 19 & Mean Difference (IV, Fixed, 95\% CI) & $7.90[1.98,13.82]$ \\
\hline 3.2 Four Weeks & 1 & 19 & Mean Difference (IV, Fixed, 95\% CI) & $12.4[7.77,17.03]$ \\
\hline $\begin{array}{l}4 \text { Functioning (GAS) all pa- } \\
\text { tients }\end{array}$ & 1 & & Mean Difference (IV, Fixed, 95\% CI) & Subtotals only \\
\hline 4.1 Two weeks & 1 & 40 & Mean Difference (IV, Fixed, 95\% CI) & $-2.30[-12.22,7.62]$ \\
\hline 4.2 Four weeks & 1 & 40 & Mean Difference (IV, Fixed, 95\% CI) & $-10.5[-22.85,1.85]$ \\
\hline $\begin{array}{l}5 \text { Functioning (GAS) non- } \\
\text { psychotic patients }\end{array}$ & 1 & & Mean Difference (IV, Fixed, 95\% CI) & Subtotals only \\
\hline 5.1 Two weeks & 1 & 21 & Mean Difference (IV, Fixed, 95\% CI) & $8.40[-5.10,21.90]$ \\
\hline 5.2 Four weeks & 1 & 21 & Mean Difference (IV, Fixed, 95\% CI) & $3.0[-14.61,20.61]$ \\
\hline $\begin{array}{l}6 \text { Functioning (GAS) psy- } \\
\text { chotic patients }\end{array}$ & 1 & & Mean Difference (IV, Fixed, 95\% CI) & Subtotals only \\
\hline 6.1 Two weeks & 1 & 19 & Mean Difference (IV, Fixed, 95\% CI) & $-14.5[-27.04,-1.96]$ \\
\hline 6.2 Four weeks & 1 & 19 & Mean Difference (IV, Fixed, 95\% CI) & $-26.1[-41.12,-11.08]$ \\
\hline
\end{tabular}

Analysis 6.1. Comparison 6 rTMS (left and high) vs ECT, Outcome 1 Symptoms (Hamilton Scale) all patients.

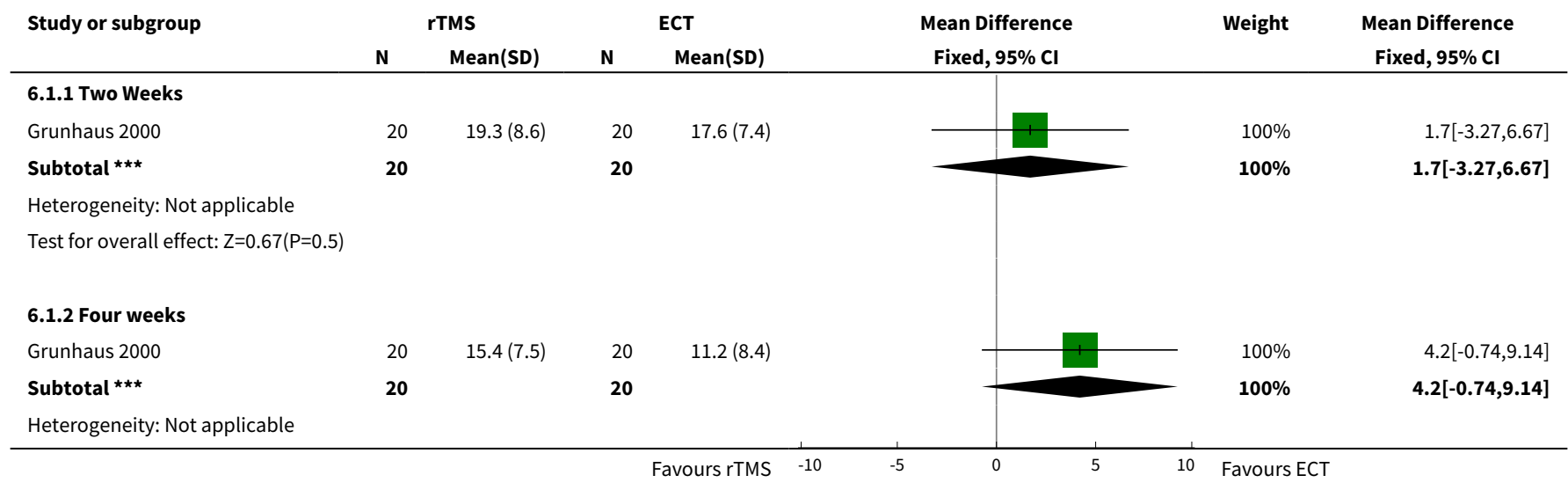




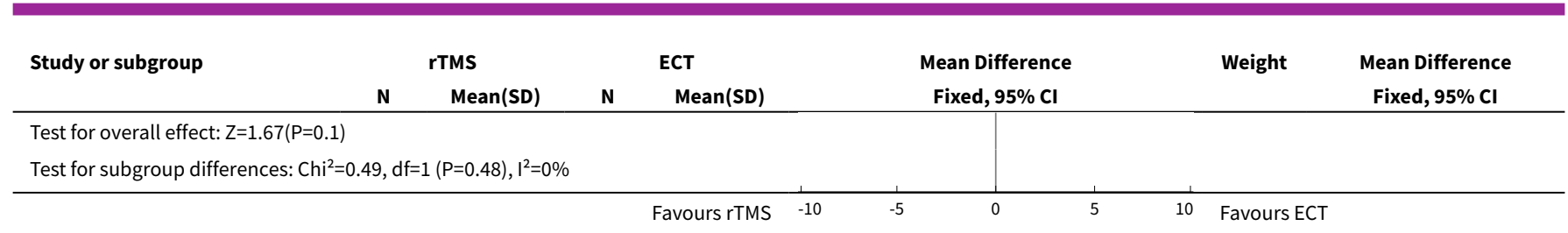

Analysis 6.2. Comparison 6 rTMS (left and high) vs ECT, Outcome 2 Symptoms (Hamilton Scale) Non-psychotic patients.

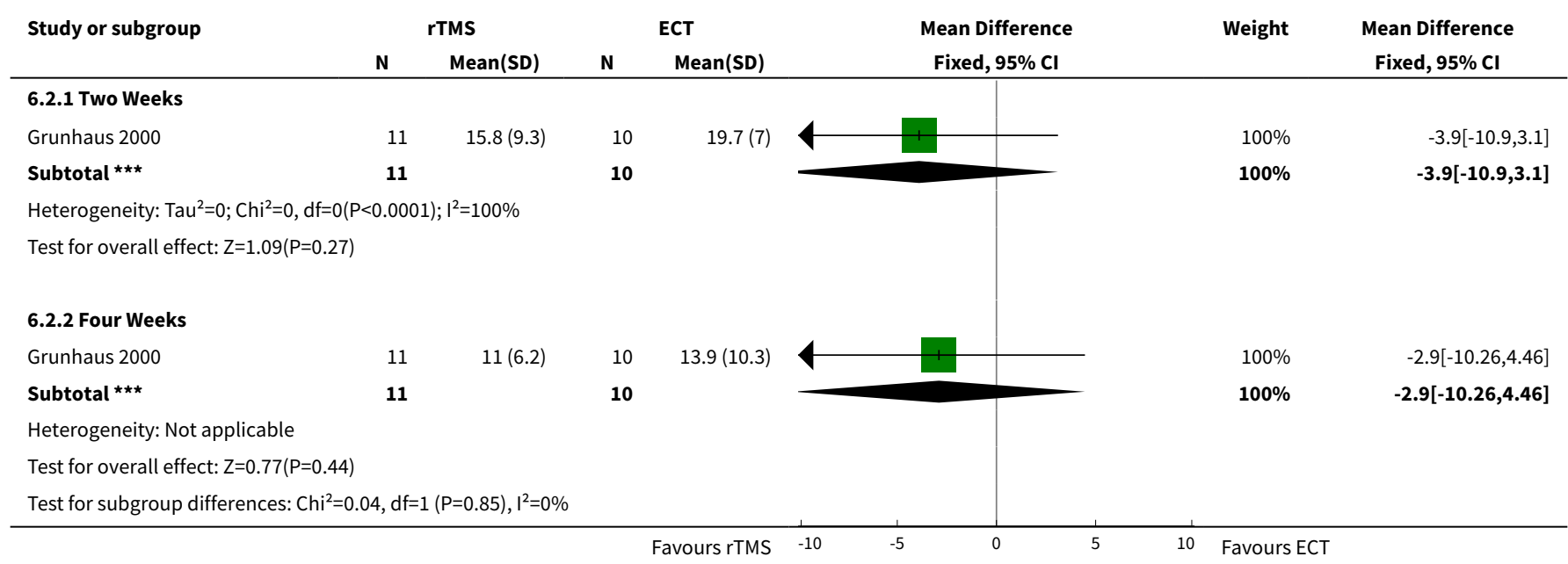

Analysis 6.3. Comparison 6 rTMS (left and high) vs ECT, Outcome 3 Symptoms (Hamilton Scale) psychotic patients.

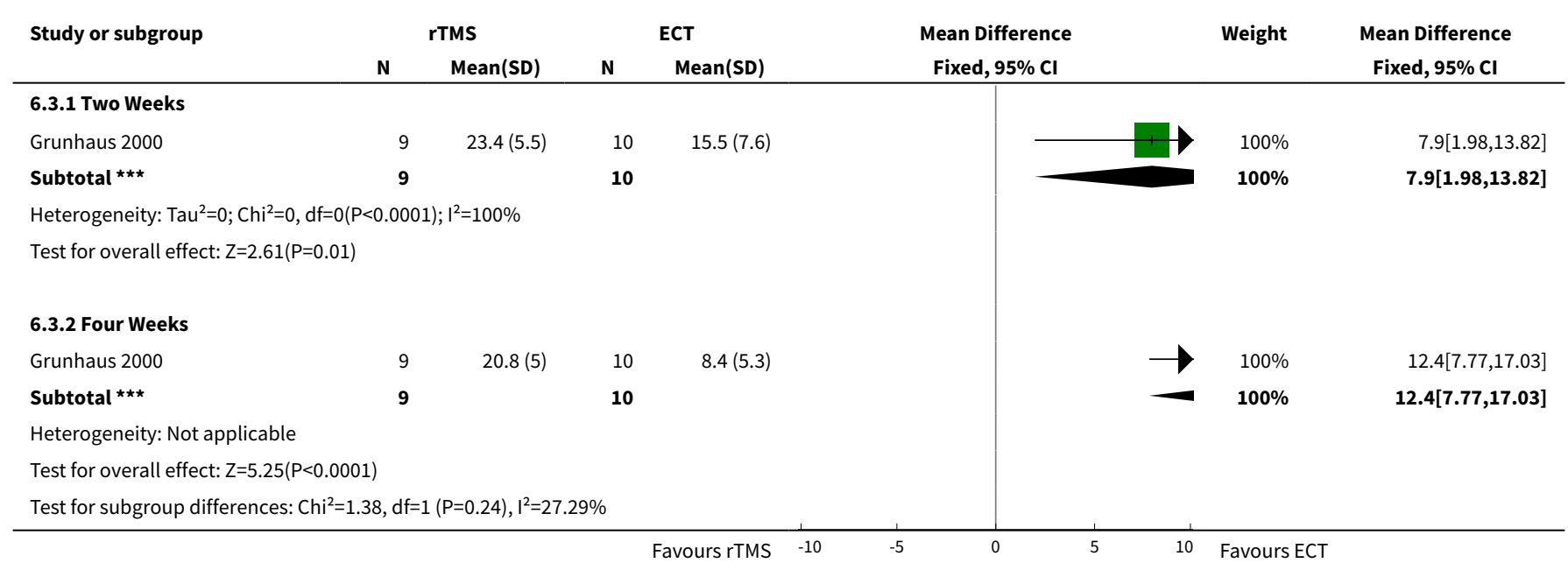


Analysis 6.4. Comparison 6 rTMS (left and high) vs ECT, Outcome 4 Functioning (GAS) all patients.

\begin{tabular}{|c|c|c|c|c|c|c|c|}
\hline \multirow[t]{2}{*}{ Study or subgroup } & \multicolumn{2}{|c|}{ rTMS } & \multicolumn{2}{|c|}{ ECT } & \multirow{2}{*}{$\begin{array}{c}\text { Mean Difference } \\
\text { Fixed, 95\% Cl }\end{array}$} & \multirow[t]{2}{*}{ Weight } & \multirow{2}{*}{$\begin{array}{c}\text { Mean Difference } \\
\text { Fixed, } 95 \% \mathrm{Cl}\end{array}$} \\
\hline & $\mathbf{N}$ & Mean(SD) & $\mathbf{N}$ & $\operatorname{Mean}(\mathrm{SD})$ & & & \\
\hline \multicolumn{8}{|l|}{ 6.4.1 Two weeks } \\
\hline Grunhaus 2000 & 20 & $44.5(14.7)$ & 20 & $46.8(17.2)$ & & $100 \%$ & $-2.3[-12.22,7.62]$ \\
\hline 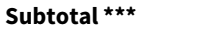 & 20 & & 20 & & & $100 \%$ & $-2.3[-12.22,7.62]$ \\
\hline \multicolumn{8}{|c|}{ Heterogeneity: Not applicable } \\
\hline \multicolumn{8}{|c|}{ Test for overall effect: $Z=0.45(P=0.65)$} \\
\hline \multicolumn{8}{|l|}{ 6.4.2 Four weeks } \\
\hline Grunhaus 2000 & 20 & $51(18.2)$ & 20 & $61.5(21.5)$ & & $100 \%$ & $-10.5[-22.85,1.85]$ \\
\hline 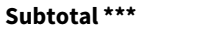 & 20 & & 20 & & & $100 \%$ & $-10.5[-22.85,1.85]$ \\
\hline \multicolumn{8}{|c|}{ Heterogeneity: Not applicable } \\
\hline \multicolumn{8}{|c|}{ Test for overall effect: $Z=1.67(P=0.1)$} \\
\hline \multicolumn{8}{|c|}{ Test for subgroup differences: $\mathrm{Chi}^{2}=1.03, \mathrm{df}=1(\mathrm{P}=0.31), \mathrm{I}^{2}=2.93 \%$} \\
\hline
\end{tabular}

Analysis 6.5. Comparison 6 rTMS (left and high) vs ECT, Outcome 5 Functioning (GAS) non-psychotic patients.

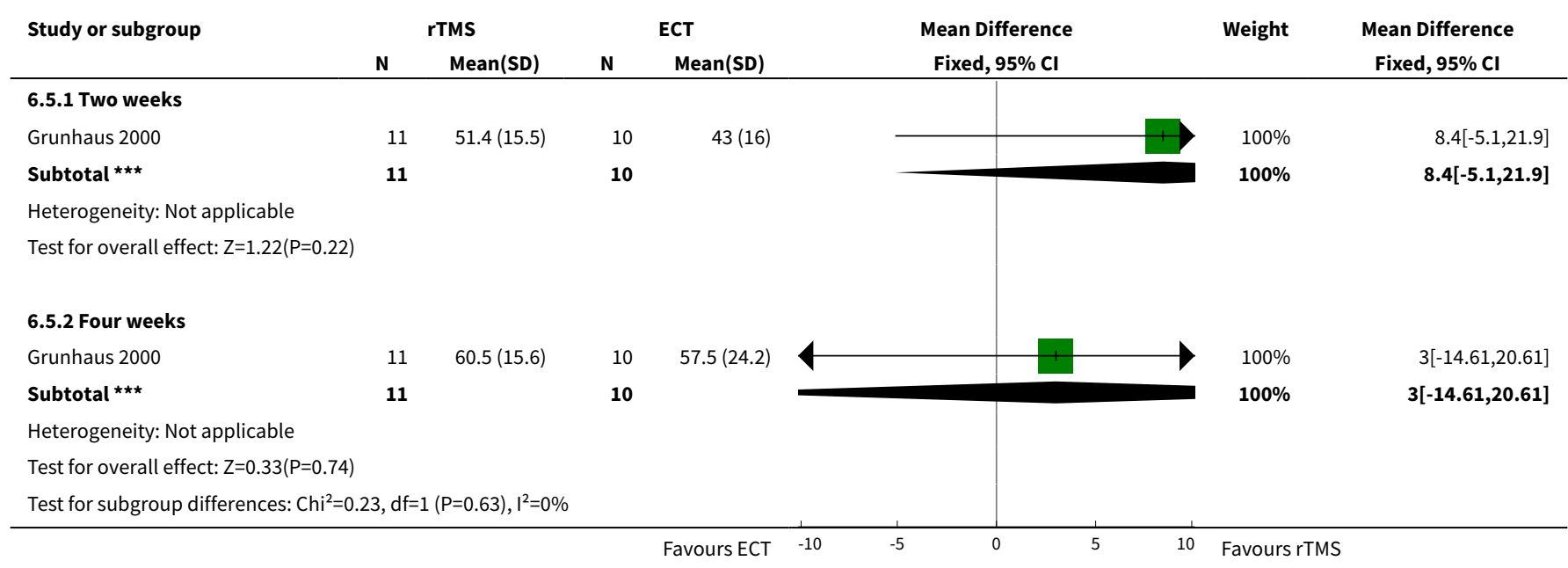

Analysis 6.6. Comparison 6 rTMS (left and high) vs ECT, Outcome 6 Functioning (GAS) psychotic patients.

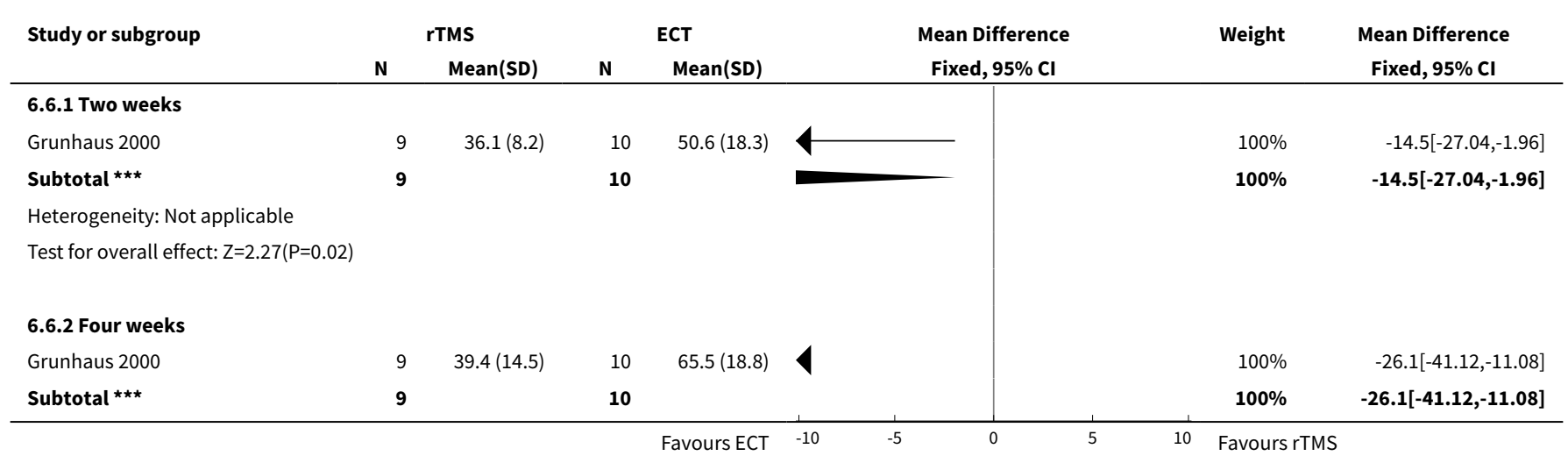




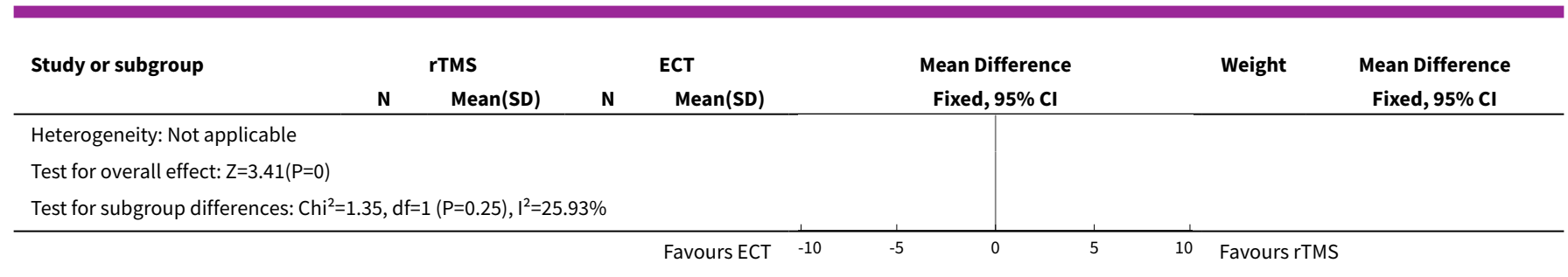

Comparison 7. Acceptability of treatment (rTMS any method of application) vs Sham TMS

\begin{tabular}{lllll}
\hline Outcome or subgroup title & No. of studies & $\begin{array}{l}\text { No. of partici- } \\
\text { pants }\end{array}$ & Statistical method & Effect size \\
\hline 1 Leaving study early for any reason & 5 & 184 & $\begin{array}{l}\text { Risk Ratio (M-H, Fixed, 95\% } \\
\text { Cl) }\end{array}$ & $0.81[0.36,1.83]$ \\
\hline
\end{tabular}

Analysis 7.1. Comparison 7 Acceptability of treatment (rTMS any method of application) vs Sham TMS, Outcome 1 Leaving study early for any reason.

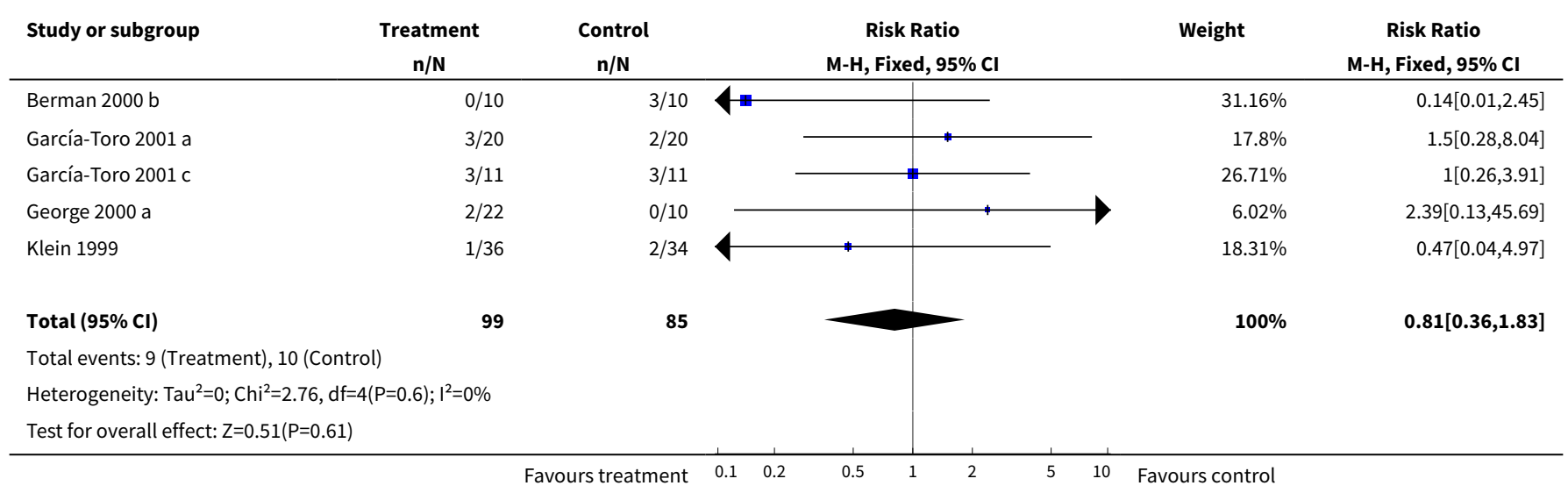

\section{Comparison 8. Baseline scores for Hamilton Depression}

\begin{tabular}{lllll}
\hline $\begin{array}{l}\text { Outcome or subgroup ti- } \\
\text { tle }\end{array}$ & No. of studies & $\begin{array}{l}\text { No. of partici- } \\
\text { pants }\end{array}$ & Statistical method & Effect size \\
\hline 1 rTMS vs Sham & 14 & 284 & Std. Mean Difference (IV, Fixed, 95\% CI) & $0.30[0.06,0.54]$ \\
\hline
\end{tabular}

Analysis 8.1. Comparison 8 Baseline scores for Hamilton Depression, Outcome 1 rTMS vs Sham.

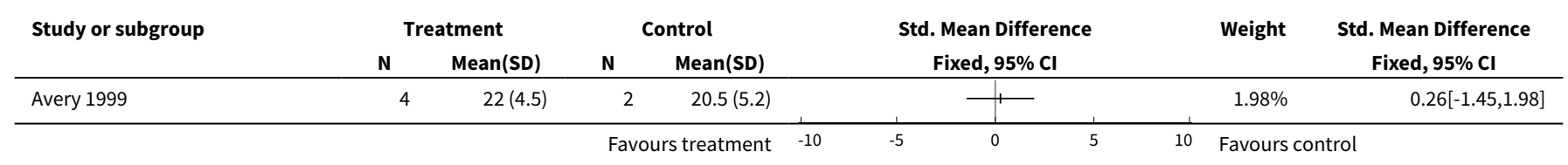




\begin{tabular}{|c|c|c|c|c|c|c|c|}
\hline \multirow[t]{2}{*}{ Study or subgroup } & \multicolumn{2}{|c|}{ Treatment } & \multicolumn{2}{|c|}{ Control } & \multirow{2}{*}{$\begin{array}{c}\text { Std. Mean Difference } \\
\text { Fixed, } 95 \% \mathrm{Cl}\end{array}$} & \multirow[t]{2}{*}{ Weight } & \multirow{2}{*}{$\begin{array}{l}\text { Std. Mean Difference } \\
\text { Fixed, } 95 \% \mathrm{Cl}\end{array}$} \\
\hline & $\mathbf{N}$ & $\operatorname{Mean}(\mathrm{SD})$ & $\mathbf{N}$ & $\operatorname{Mean}(S D)$ & & & \\
\hline Berman $2000 \mathrm{~b}$ & 10 & $37.1(9.7)$ & 10 & $37.3(8.5)$ & $\rightarrow$ & $7.59 \%$ & $-0.02[-0.9,0.86]$ \\
\hline Eschweiler 2000 & 5 & $27.4(4.6)$ & 5 & $20.2(3.8)$ & 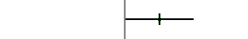 & $2.55 \%$ & $1.54[0.03,3.05]$ \\
\hline García-Toro 2001 a & 17 & $27.1(6.7)$ & 18 & $25.6(4.9)$ & + & $13.15 \%$ & $0.25[-0.41,0.92]$ \\
\hline García-Toro 2001 c & 11 & $25.9(6.4)$ & 11 & $26.6(6.4)$ & $\rightarrow$ & $8.33 \%$ & $-0.11[-0.94,0.73]$ \\
\hline George 1997 & 7 & $30(4)$ & 5 & $26(3)$ & - & $3.73 \%$ & $1.02[-0.23,2.27]$ \\
\hline George 2000 a & 20 & $28.1(6)$ & 10 & $23.8(4.1)$ & + & $9.41 \%$ & $0.77[-0.02,1.55]$ \\
\hline Haag 1997 & 6 & $30.2(9.5)$ & 6 & $22.2(8.8)$ & 1 & $4.06 \%$ & $0.81[-0.39,2]$ \\
\hline Kimbrell 1999 & 5 & $25(6.6)$ & 3 & $24.3(6.8)$ & 1 & $2.84 \%$ & $0.09[-1.34,1.52]$ \\
\hline Kimbrell 1999b & 5 & $34.4(8)$ & 3 & $24.3(6.8)$ & 1 & $2.18 \%$ & $1.15[-0.48,2.79]$ \\
\hline Klein 1999 & 35 & $25.8(5.6)$ & 32 & $25.3(6.4)$ & \# & $25.34 \%$ & $0.08[-0.4,0.56]$ \\
\hline Loo 1999 & 9 & $21.4(6.6)$ & 9 & $25.1(5.7)$ & $\rightarrow$ & $6.49 \%$ & $-0.57[-1.52,0.38]$ \\
\hline Mosimann In Press & 15 & $28.7(4.6)$ & 9 & $24.6(7.3)$ & + & $7.99 \%$ & $0.69[-0.16,1.55]$ \\
\hline Padberg 1999b & 6 & $26.7(9.4)$ & 6 & $22.2(8.8)$ & 1 & $4.38 \%$ & $0.46[-0.7,1.61]$ \\
\hline Total *** & 155 & & 129 & & $\downarrow$ & $100 \%$ & $0.3[0.06,0.54]$ \\
\hline \multicolumn{8}{|c|}{ Heterogeneity: $\mathrm{Tau}^{2}=0 ; \mathrm{Chi}^{2}=13.37, \mathrm{df}=13(\mathrm{P}=0.42) ; \mathrm{I}^{2}=2.77 \%$} \\
\hline \multicolumn{8}{|c|}{ Test for overall effect: $\mathrm{Z}=2.41(\mathrm{P}=0.02)$} \\
\hline
\end{tabular}

\section{FEEDBACK}

\section{Transcranial magnetic stimulation for treating depression, 5 April 2018}

\section{Summary}

Why is there not a more updated review?

There are four versions of Non-invasive stimulation for pain, but only this for rTMS for depression (an FDA cleared treatment). It is misleading to insurers and the public.

\section{Reply}

Many thanks for your comment. Feedback on reviews is normally dealt with by the relevant review author, but in this case as your query relates more to an organisational issue I am responding on behalf of the Cochrane Common Mental Disorders Group. The Cochrane Common Mental Disorders Group is currently undertaking an assessment of all existing and planned reviews and protocols, including those relating to depression. We will contact authors over the coming months to identify where there is capacity to update reviews. Your comment is helpful to us in informing this process. I have copied this response to the review authors in case they wish to comment further. Many thanks for your feedback.

\section{Contributors}

Submitter name: Michelle Cochran

Affiliation: Clinicial TMS Society

Affiliation with or involvement in any organisation with a financial interest in the subject matter of the comment: I am the current president of the Clinical TMS Society

Response: Jessica Hendon

Declarations of interest: Jessica Hendon is the Managing Editor of the Cochrane Common Mental Disorders Group. No other conflict of interest declared.

\section{WHAT' S NEW}




\begin{tabular}{lll}
\hline Date & Event & Description \\
\hline 31 October 2018 & Feedback has been incorporated & Feedback comment and response added \\
\hline
\end{tabular}

\section{H I S T O R Y}

Protocol first published: Issue 1, 2002

Review first published: Issue 2, 2002

\begin{tabular}{lll}
\hline Date & Event & Description \\
\hline 6 November 2008 & Amended & Converted to new review format \\
\hline 12 July 2001 & $\begin{array}{l}\text { New citation required and conclusions } \\
\text { have changed }\end{array}$ & Substantive amendment \\
\hline
\end{tabular}

\section{DECLARATIONS OF INTEREST}

Dr Schlaepfer is involved in one of the two ongoing included studies in the review.

\section{SOURCES OF SUPPORT}

\section{Internal sources}

- Institut de Recerca del Hospital de la Santa Creu i Sant Pau, Spain.

- Centro Cochrane Iberoamericano, Spain.

- Hospital de la Santa Creu i Sant Pau, Spain.

\section{External sources}

- Instituto de Salud Carlos III (00/10099), Spain.

\section{NOTES}

The current authors are not currently working on this review and it may be passed on to a new group of review authors.

\section{N DEX TERMS}

\section{Medical Subject Headings (MeSH)}

Depression [ ${ }^{\star}$ therapy]; Physical Stimulation [methods]; Transcranial Magnetic Stimulation [ ${ }^{\star}$ therapeutic use]

\section{MeSH check words}

Humans 